EXPERIMENTAL INVESTIGATIONS INTO FLUID-STRUCTURE INTERACTIONS BETWEEN A CANTILEVER BEAM AND AXIALLY FLOWING WATER AT DIFFERENT MASS FLOW RATES

\author{
By \\ Bryan Hudson \\ BEng, Ryerson University, 2011
}

\author{
A thesis \\ presented to Ryerson University \\ in partial fulfillment of the \\ requirements for the degree of \\ Master of Applied Science \\ in the Program of \\ Mechanical and Industrial Engineering
}

Toronto, Ontario, Canada, 2015

CBryan Hudson 2015 


\section{Author's Declaration}

I hereby declare that I am the sole author of this thesis.

I authorize Ryerson University to lend this thesis to other institutions or individuals for the purpose of scholarly research.

I further authorize Ryerson University to reproduce this thesis by photocopying or by other means, in total or in part, at the request of other institutions or individuals for the purpose of scholarly research. 


\title{
Bryan Hudson
}

EXPERIMENTAL INVESTIGATIONS INTO FLUID-STRUCTURE INTERACTIONS BETWEEN A CANTILEVER BEAM AND AXIALLY FLOWING WATER AT DIFFERENT MASS FLOW RATES

\author{
Master of Applied Science \\ 2015 \\ Mechanical and Industrial Engineering \\ Ryerson University
}

\begin{abstract}
This thesis presents an experimental investigation into the response of a cantilever beam experiencing axial flow induced vibrations with the free boundary condition at upstream. The acceleration of the beam was captured at two locations using MEMS based accelerometers. The experimental results were compared with known characteristics of each of the three types of responses known to result from flow induced vibrations in axial flow. The observed phenomena can be classified as non-resonant buffeting response driven by the turbulent flow of the fluid.
\end{abstract}




\section{Acknowledgements}

I would like to thank Dr. Shudong Yu for not only giving me this opportunity but for his insights and guidance through the process of producing this thesis.

I would also like to thank Candu Energy and NSERC for providing the funding necessary to accomplish this work. 


\section{Table of Contents}

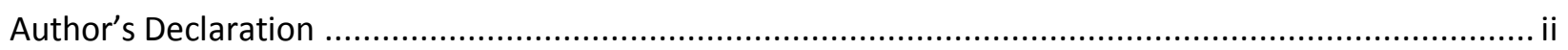

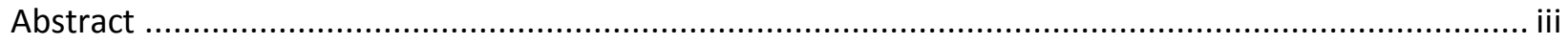

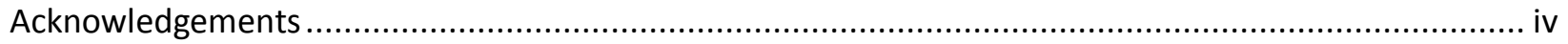

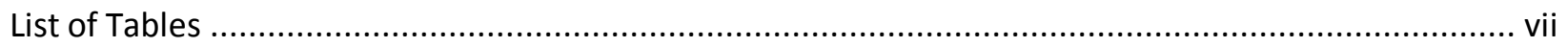

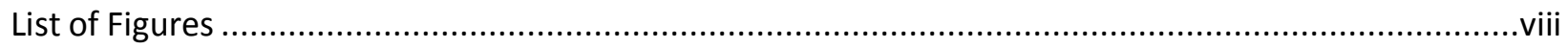

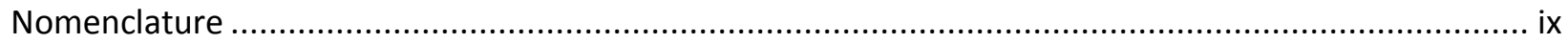

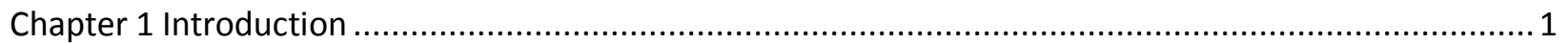

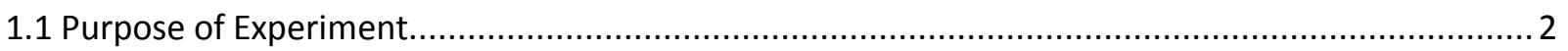

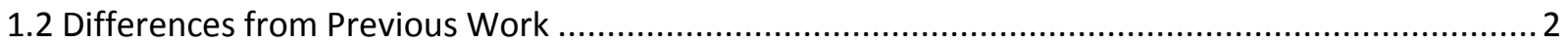

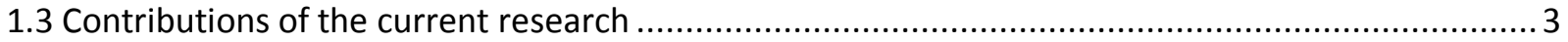

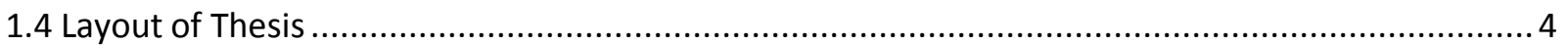

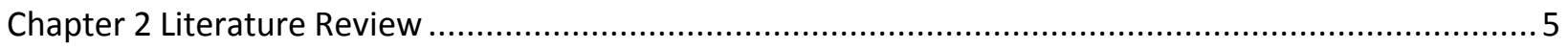

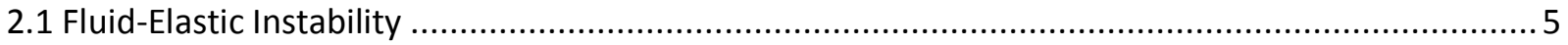

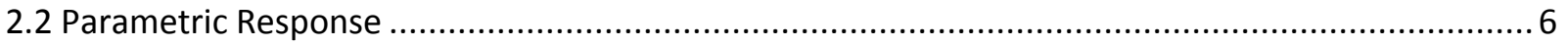

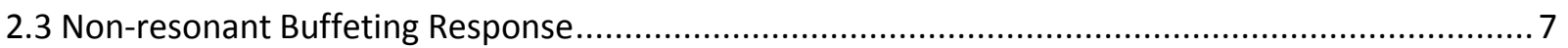

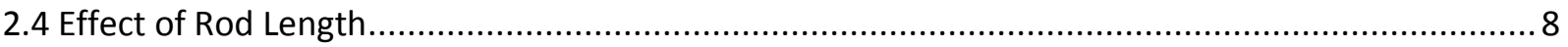

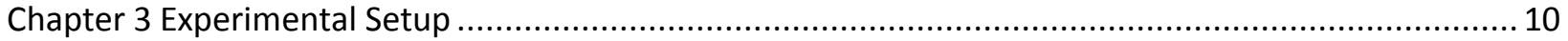

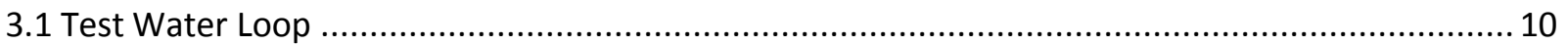

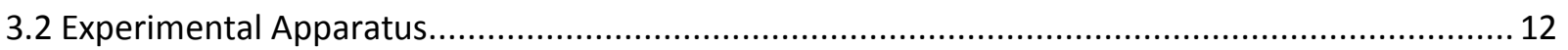

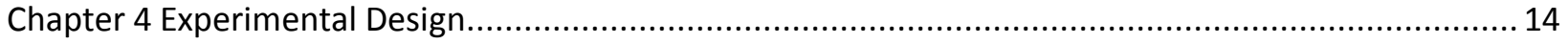

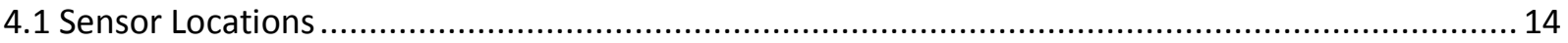

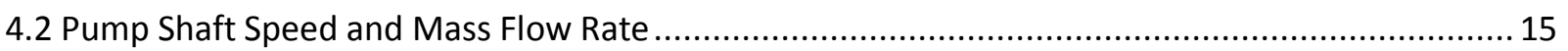

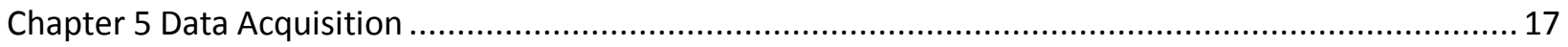

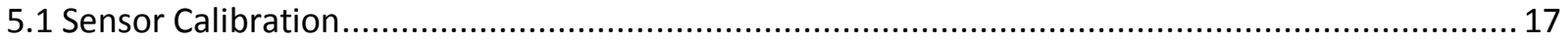

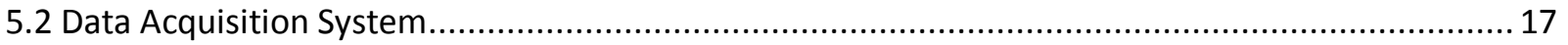

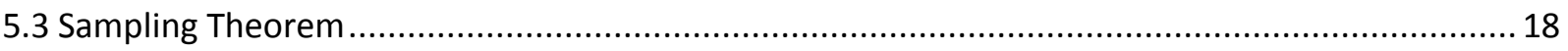

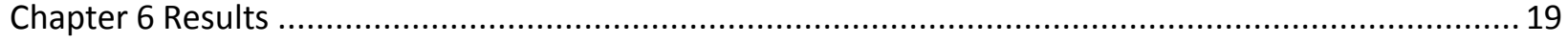

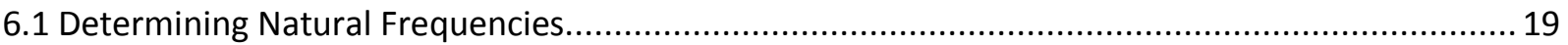

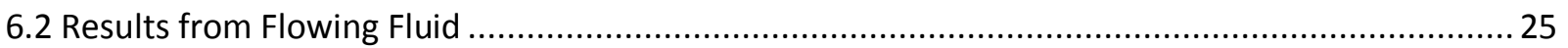

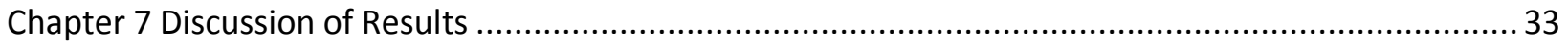


7.1 Fluid-Elastic Instability

7.2 Parametric Response .

7.3 Non-Resonant Buffeting Response 43

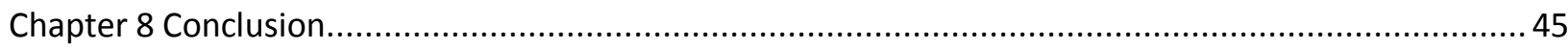

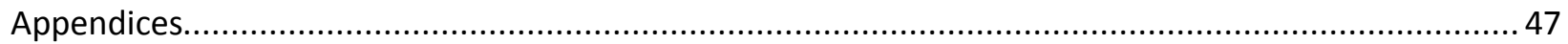

Appendix 1: MATLAB program used to provide composite plots ................................................ 47

Appendix 2: MATALB program for determining the mode shapes .............................................. 53

Appendix 3: Program used to generate acceleration vs. time graphs ........................................ 54

Appendix 4: Positions of sensors during gravity calibration ...................................................... 56

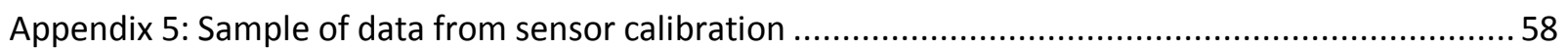

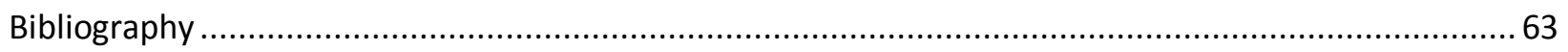




\section{List of Tables}

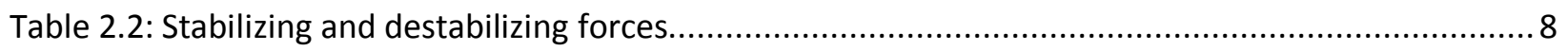

Table 4.1: Controller speeds, shaft rotation frequencies, and mass flow rates ................................... 16

Table 6.1: Calculated natural frequency vs. measured frequencies in power spectrum ........................ 25 


\section{List of Figures}

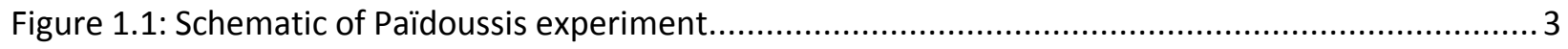

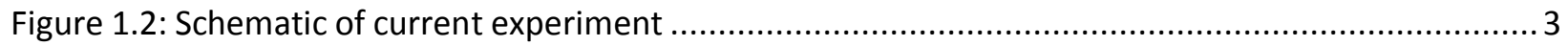

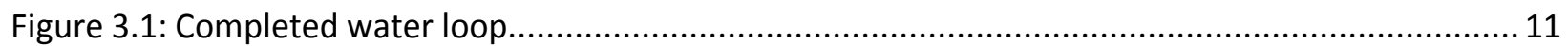

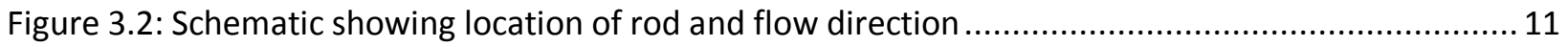

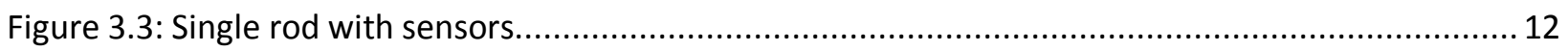

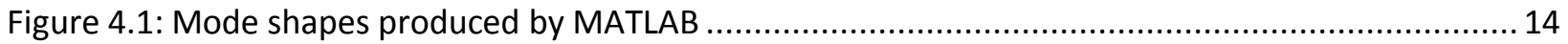

Figure 6.1: Acceleration vs. time signal of impact excitation in air .................................................. 20

Figure 6.2: Acceleration vs. time signal of impact excitation in water ............................................... 20

Figure 6.3: Acceleration power spectrum density from impact air test ............................................. 21

Figure 6.4: Acceleration power spectrum density from impact water test.......................................... 22

Figure 6.5: Displacement power spectrum density from impact air test ............................................ 23

Figure 6.6: Displacement power spectrum density from impact water test ......................................... 24

Figure 6.7: Acceleration vs time graphs for $0.625 \mathrm{~L}$ position in vertical direction .................................... 25

Figure 6.8: Acceleration vs time graphs for $0.625 \mathrm{~L}$ position in horizontal direction ............................ 26

Figure 6.9: Acceleration vs time graphs for $0.25 \mathrm{~L}$ position in vertical direction .................................. 26

Figure 6.10: : Acceleration vs time graphs for $0.25 \mathrm{~L}$ position in horizontal direction............................ 27

Figure 6.11: Composite acceleration power spectrum densities from $0.625 \mathrm{~L}$ in vertical direction ......... 28

Figure 6.12: Composite acceleration power spectrum densities from $0.625 \mathrm{~L}$ horizontal direction ......... 28

Figure 6.13: Displacement power spectrum densities computed from figure 6.7 ............................. 29

Figure 6.14: Displacement power spectrum densities computed from figure 6.8 .................................. 29

Figure 6.15: Composite acceleration power spectrum densities from $0.25 \mathrm{~L}$ in vertical direction ........... 30

Figure 6.16: Composite acceleration power spectrum densities from $0.25 \mathrm{~L}$ in horizontal direction ........ 31

Figure 6.17: Displacement power spectrum densities calculated from figure 6.11 ............................. 31

Figure 6.18: Displacement power spectrum densities calculated from figure 6.12 .............................. 32

Figure 7.1: Dimensionless displacement vs. dimensionless velocity at tip sensor in vertical direction..... 34

Figure 7.2: Dimensionless displacement vs. dimensionless velocity at tip sensor in horizontal direction 34

Figure 7.3: Dimensionless displacement vs. dimensionless velocity at base sensor in vertical direction . 35

Figure 7.4: Dimensionless displacement vs. dimensionless velocity at base sensor in horizontal direction

35

Figure 7.5: Acceleration power spectrum density with vane passing frequency marked........................ 41

Figure 7.6: Acceleration power spectrum density under operation conditions with the acoustic frequency marked. 


\section{Nomenclature}

\begin{tabular}{|c|c|c|}
\hline$A$ & Area of the rod & $m$ \\
\hline$A P S D$ & Acceleration power spectrum density value & $G^{2} / H z$ \\
\hline$C_{B}$ & Base drag coefficient & \\
\hline$C_{T}$ & Tangential drag coefficient & \\
\hline$D P S D$ & Displacement power spectrum density value & $m^{2} / \mathrm{Hz}$ \\
\hline$D$ & Diameter of structure & $m$ \\
\hline$d_{i}$ & Inner diameter of rod & $m$ \\
\hline$d_{o}$ & Outer diameter of rod & $m$ \\
\hline$E$ & Young's modulus & $p a$ \\
\hline$f_{\text {passing }}$ & Vane passing frequency & $H z$ \\
\hline$f_{\text {shaft }}$ & Shaft rotation frequency & $H z$ \\
\hline$f_{\text {voltage }}$ & Voltage frequency & $H z$ \\
\hline$I$ & Second moment of area of structure & $m^{4}$ \\
\hline$L_{c}$ & Compression length & $m$ \\
\hline$l_{s}$ & Length of structure & $m$ \\
\hline$l$ & Effective length & \\
\hline$n$ & Motor rotation frequency & $R P M$ \\
\hline$P$ & Number of motor poles & \\
\hline$U$ & Free stream fluid velocity & $\mathrm{m} / \mathrm{s}$ \\
\hline$u$ & Dimensionless velocity & \\
\hline$V_{i}$ & Voltage at time step i & $V$ \\
\hline$V_{\text {mean }}$ & Mean voltage of raw data & $V$ \\
\hline
\end{tabular}


$\beta_{n} l \quad$ Weighted frequencies

$\eta \quad$ Dimensionless displacement

$\rho \quad$ Fluid density

$\mathrm{kg} / \mathrm{m}^{3}$

$\omega \quad$ Frequency corresponding to power spectrum density values

$\mathrm{rad} / \mathrm{s}$ 


\section{Chapter 1 Introduction}

Fluid structure interactions, such as flow induced vibrations, have been a subject of study since the first half of the $20^{\text {th }}$ century. The majority of the research has been in the area of flow induced vibrations initiated by a fluid moving in cross flow, or perpendicular to, a structure. Since the second half of the $20^{\text {th }}$ century axial flow induced vibrations have become a major area of study in such areas as power generation, flexible towed barges, and towed acoustic arrays. The three types of responses that exist as a result of flow induced vibrations in axial flow are [1]:

1. Non-resonant buffeting response

2. Parametric resonances

3. Fluid-elastic instability

Axial flow induced vibrations has been of particular interest to the power generation industry. CANDU nuclear reactors experience fretting in their fuel channel components which is caused by flow induced vibrations. Information provided by CANDU Energy Inc. stated that this fretting wear is taking place at the most upstream fuel bundles. Previous experiments have been done investigating flow induced vibrations of 1 or 2 simulated CANDU fuel bundles [2].

In an attempt to provide a more realistic simulation of a CANDU fuel channel 6 small scale bundles were produced to investigate axial flow induced vibrations. These simulations proved to be fruitless so a simpler structure was designed as an allegory to the 13 bundle CANDU fuel string. A single rod was used as the allegory in order to study the phenomena of 
axial flow induced vibrations of a slender structure. Since the fretting is taking place at the upstream position and with the assumption that bundles at the downstream shield plug experience no motion a cantilever beam design was used. The clamped boundary condition would be downstream and the free boundary condition would be upstream to simulate the motion causing the fretting wear.

\subsection{Purpose of Experiment}

This thesis focuses on determining the response of the observed vibration in a single cantilever rod in axial flow with the free boundary condition at upstream. The data gathered was compared with the known characteristics of three types of flow induced vibration response: fluid-elastic instability, parametric resonance, and non-resonant buffeting to determine which of these responses is observed in the beam vibrations. The experiments are also meant to provide meaningful quantitative data for future work in theoretical and predictive analysis of flow induced vibrations of CANDU fuel strings.

\subsection{Differences from Previous Work}

Païdoussis' experiments were conducted using optical measurements, which Peri later improved on by using in-situ measurements from MEMS accelerometers [3]. Both of their experiments were based on a cantilevered cylinder where the fluid, water in this case, flowed from the clamped boundary condition to the free boundary condition. The difference between this thesis and their work is that the fluid flows from the free boundary condition to the clamped boundary condition thereby changing the nature of the fluid structure interaction. 
Figures 1.1 and 1.2 below illustrate the difference with the arrow indicating the direction of the mean bulk flow.

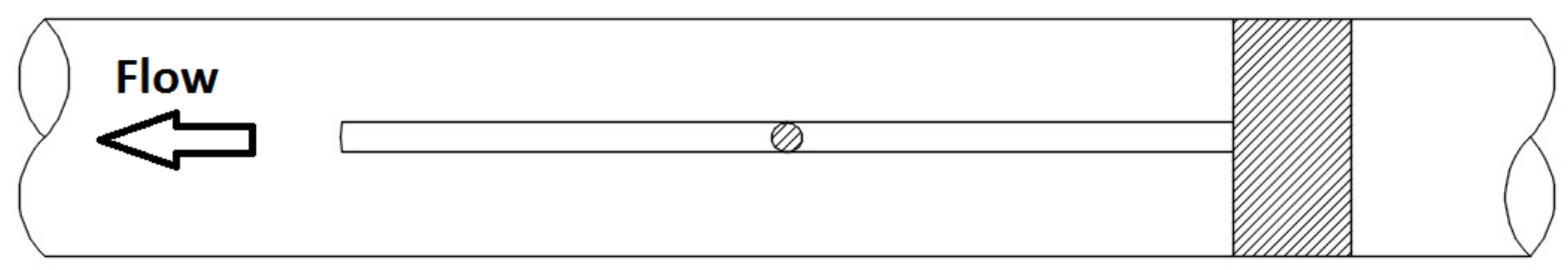

Figure 1.1: Schematic of Païdoussis' experiment

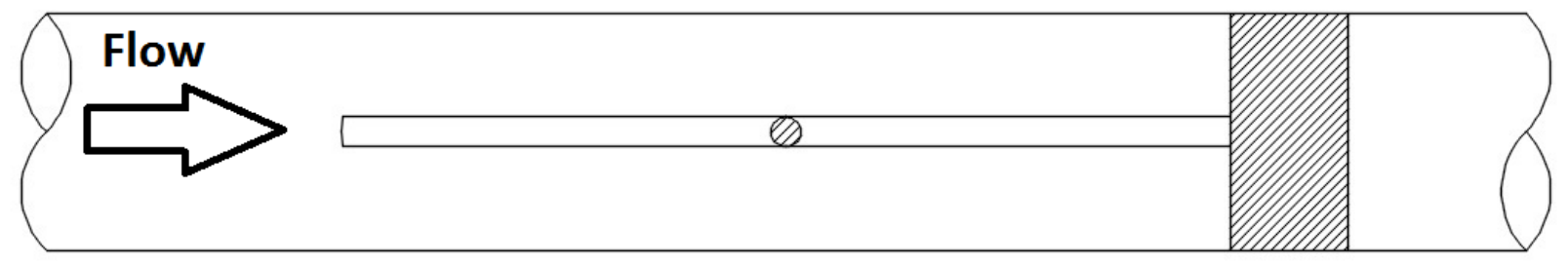

Figure 1.2: Schematic of current experiment

Like Peri, the experiments conducted were quantified through in-situ measurements from MEMS accelerometers. Païdoussis and Peri also used elastomers to construct the cylinder used in their experiments. The material used for this experiment is copper.

\subsection{Contributions of the current research}

The experiments done in the available literature study flow induced vibrations of a cylinder in axial flow with the clamped boundary condition upstream from the free boundary 
condition. This design comes from the original study done by Hawthorne who was concerned about the stability of a flexible towed barge. This analysis became the basis for the original experiments done by Païdoussis and much of the literature on this subject that has followed [4]. The single rod in this experiment was designed as an allegory to a CANDU 13 bundle fuel string where all thirteen bundles are supported downstream by a shield plug. These experiments will provide data that can be used as a comparison in future modeling and predictive analyses of axial flow induced vibrations and in particular CANDU fuel strings.

\subsection{Layout of Thesis}

The following sections provide a literature review as well as describe the design and construction of the physical experimental apparatus, the design of experimental procedure, a description of the data retrieval equipment, the methods and tools of analysis that were used, and the description of the response phenomena that was drawn from the analysis done on the gathered data. 


\section{Chapter 2 Literature Review}

The description of a fluid structure interaction between a fluid and a rod is as follows [5]:

1. The moving fluid creates a load on the rod

2. The rod deforms under the load

3. The deformed rod now alters the fluid

4. The altered fluid creates a new load

This type of interaction occurs over and over again in a cyclical fashion. According to Païdoussis and Lopes the dynamic behaviour of the rod in axial flow is dependent not only on fluid velocity which is parallel to the material axis of the rod but also on the boundary conditions at either end of the rod [5]. For example, a pinned/pinned rod experiences both oscillatory and non-oscillatory, instabilities in the rod's first mode and these phenomena may extend into higher modes if the fluid velocity is sufficient [5]. A cantilevered rod, on the other hand, may be subject to non-oscillatory instabilities in its first mode and oscillatory instabilities in its higher modes [6]

\subsection{Fluid-Elastic Instability}

The amplitude of vibration increases slowly with increasing flow velocity until reaching the fluid velocity where fluid-elastic instabilities occur, called the critical velocity. After this point the amplitude of vibrations increases rapidly with increasing fluid velocity. The combining of 
the fluid velocity with the material properties of the structure yields the following nondimensionalized velocity parameter [1]:

$$
u=\sqrt{\frac{\rho A}{E I}} U l_{s}
$$

Fluid-elastic instabilities occur when the non-dimensional velocity achieves a value of approximately 2. Based on the above formulation, it can be concluded that materials with a low Young's modulus, such as rubber and silicone, require a much smaller fluid velocity to induce fluid-elastic instabilities than materials with a higher Young's modulus, such as metallic materials. The difference in the required fluid velocities can sometimes be on the order of $50-$ 100 times smaller for materials with a low Young's modulus [1]. For this reason, Païdoussis used silicone rubber halves in his experiments with a metal sheet attached between them to eliminate vertical motion and prevent sagging [1].

\subsection{Parametric Response}

Parametric response consists of the structure being excited by a fluid flow that has a repeating and regular perturbation from mean bulk flow [1]. Such perturbations in a confined flow, such as the experiment performed in this paper, can come from acoustic energy generated by a pump in the form of either a pressure pulse produced as the vanes of the pump pass the pump's outlet or a standing wave generated by the operation of the pump and transmitted through the pipework itself. A second source of parametric resonance is the presence of two-phase flow in the pipe being considered [1]. This experiment was designed to reduce the standing wave effects generated by the pump so the response of the rod was not 
affected to any great degree by this phenomenon. However this left the pressure pulsation generated by the pump as each vane passed the outlet as a potential source of excitation. As each vane passes the outlet of the pump a small pressure pulse is created [7]. If the pulse has sufficient energy and the right frequency, the pressure pulse can be a source of excitation [1]. The procedure with which the experiment was conducted left little opportunity for two-phase flow to occur since the piping was thoroughly flooded before measurements were taken. Because of this two-phase flow was not considered in this paper.

\subsection{Non-resonant Buffeting Response}

Non-resonant buffeting response, also called turbulence induced vibrations, tend to be small, typically on the order of 100 - 1000 less than the diameter of the rod. Pressure fluctuations in the fluid act as the excitation force for the rod in a forced vibration system [1].

The pressure field consists of both near field and far field effects. Near field effects are local pressure fluctuations generated by boundary layers or flow disturbances, such as values, bends, reducers etc. Far field components are propagating disturbances, such as acoustic waves. The most accurate predictive models have to take both into account [8]

A predictive model of the root mean square amplitude is not part of this work, since to achieve the most accurate prediction of the fluid pressure field it is necessary to perform in situ measurements of the pressure field. [8]. The equipment needed to perform these measurements was not available during this experiment. 


\subsection{Effect of Rod Length}

The length of the rod is another critical factor affecting the dynamics of the rod. Calculations have shown that the critical velocities for both non-oscillatory instability and oscillatory instability increase as the length of the rod increases [9]

For short rods the normal force balance acting on the rod is divided into two categories: stabilizing and destabilizing [9]:

Table 2.1: Stabilizing and destabilizing forces

\begin{tabular}{|c|c|}
\hline Destabilizing Forces & Stabilizing Forces \\
\hline Negative added stiffness & Bending stiffness at the base \\
\hline Lift force at free end & Drag at the free end \\
\hline
\end{tabular}

The negative bending stiffness is proportional to the square of the mean stream fluid velocity. The lift force is proportional to the product of the lift coefficient and the product of the mean stream fluid velocity. The lift coefficient values range from 0 and 1 . A blunt end would have a lift coefficient of 0 and a streamlined tip a lift coefficient of 1 . The bending stiffness at the base is the product of the materials Young's modulus and the second moment of area for the structures geometry. The drag force at the free end is proportional to the product of 1 minus the lift coefficient and the square of the free stream fluid velocity. For long rods a $5^{\text {th }}$ force is added. That force is the axial friction which also acts as a stabilizing force. A very long rod is classified as such when the following relationship is not small [9]: 


$$
l=\frac{L}{L_{c}}
$$

Where $L_{c}$ is the compression length at which the flow induced tension in the rod and the flow induced compressive load exactly balance. The value of which is calculated with the following formula [9]:

$$
L_{c}=\frac{D\left(\pi-2 C_{b}\right)}{2 C_{T}}
$$

If the ratio of length to compression length is greater than 1 then a point exists along the material axis of the structure where the tension force from fluid friction is balanced by an effective compressive force which is the added stiffness of the rod [9]. 


\section{Chapter 3 Experimental Setup}

The apparatus used in the experiments is a modification of an older experiment used for similar research. The original apparatus consisted of a closed loop of 4 inch PVC pipe with a 10hp, $18 \mathrm{~m}$ head pump at one end and a flow meter at the other. One section of PVC pipe was clear and was used as a test chamber. For this experiment, this section was reduced in diameter from 4 inches to 2 inches. As much of the original setup as possible was reused and modified for the 2 inch pipe in order to keep costs down as well as expedite the production time.

\subsection{Test Water Loop}

The experiment test loop was designed to eliminate standing waves that existed in the previous closed loop setup. To accomplish this, a 500 gallon tank was added to the system to act as an acoustic sink. This would remove the standing waves as a source of acoustic energy but leave the pressure pulsation of the pump as an excitation source for the beam vibration as well as allowing the investigation of fluid/structural interaction based vibrations. The remainder of the water loop, shown in figure 3.1 below, consists of the 500 gallon tank, the test section of 2 inch clear PVC pipe, a 10Hp $18 \mathrm{~m}$ head pump, 4 inch black PVC pipe, and a flow meter. 


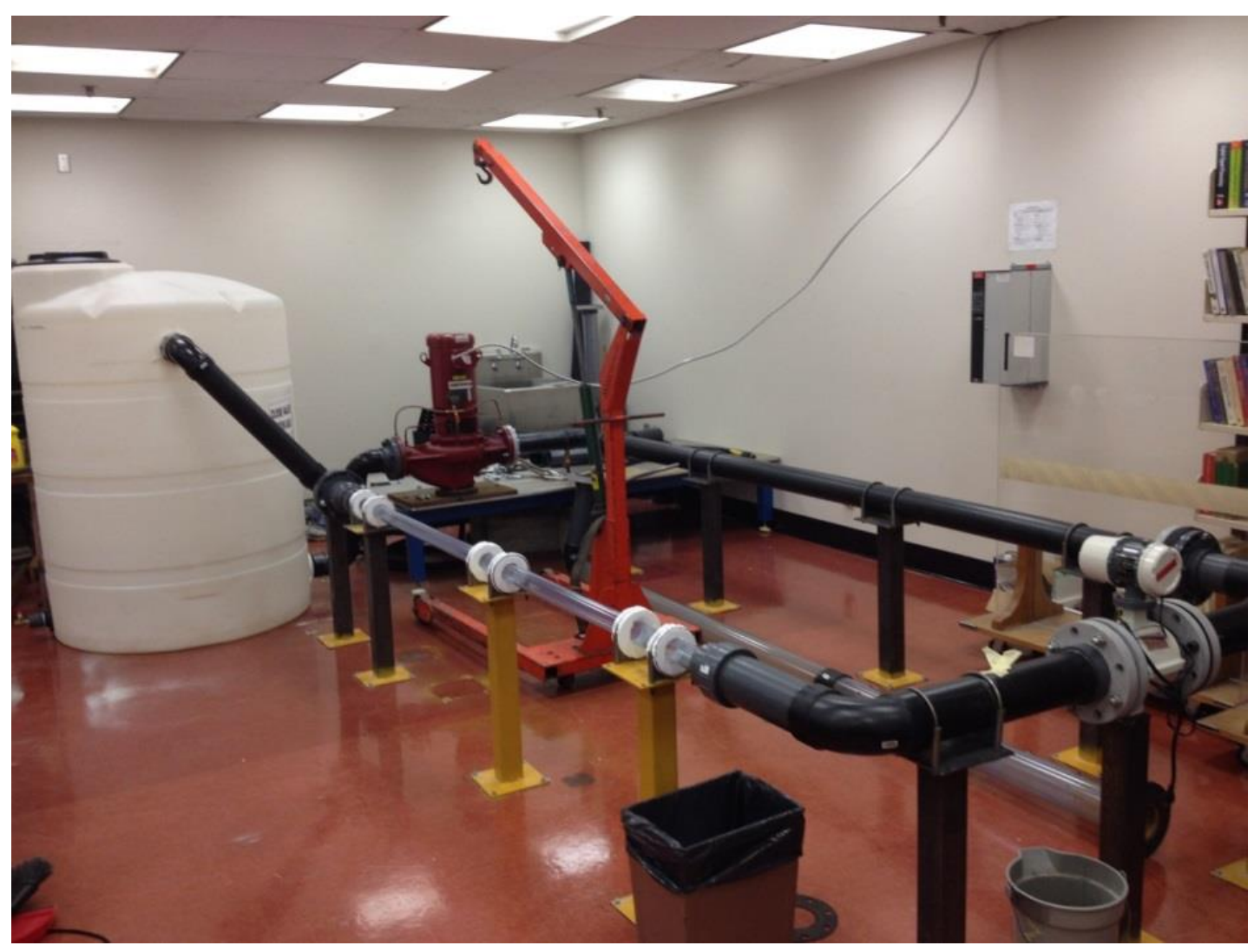

Figure 3.1: Completed water loop

Figure 3.2 below shows a schematic with the position of the apparatus and with the flow directions indicated by arrows.

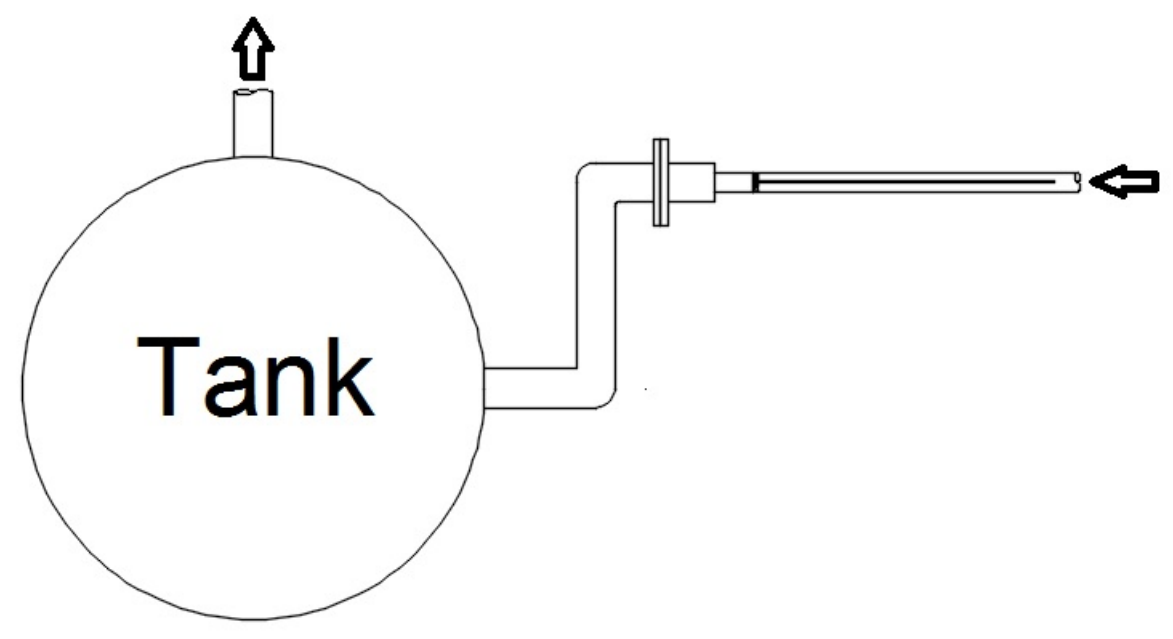

Figure 3.2: Schematic showing location of rod and flow direction 


\subsection{Experimental Apparatus}

The experimental beam consists of a single hollow copper pipe $77.5 \mathrm{~cm}$ long with a $0.635 \mathrm{~cm}$ outer diameter and a $0.483 \mathrm{~cm}$ inner diameter. The pipe was sealed at the free end so the rod was filled with air during the experiments. This pipe is held in place using a selftapping screw and four washers attached to two plates which were water jet cut with a series of holes. This whole assembly was attached to a PVC insert which itself is placed inside a 2 inch union joint. This plate/washer assembly was treated as a clamped boundary condition and the sealed blunt end created the free boundary condition. Out of plane bending may still exist in the plates but it has been assumed that the out of plane bending is of negligible effect to the rod motion and therefore has been treated as a clamped boundary condition. The union section of the test chamber is removable to allow easy placement and removal. Figure 3.2 below shows the single hollow rod and its support with the sensors mounted at two locations.

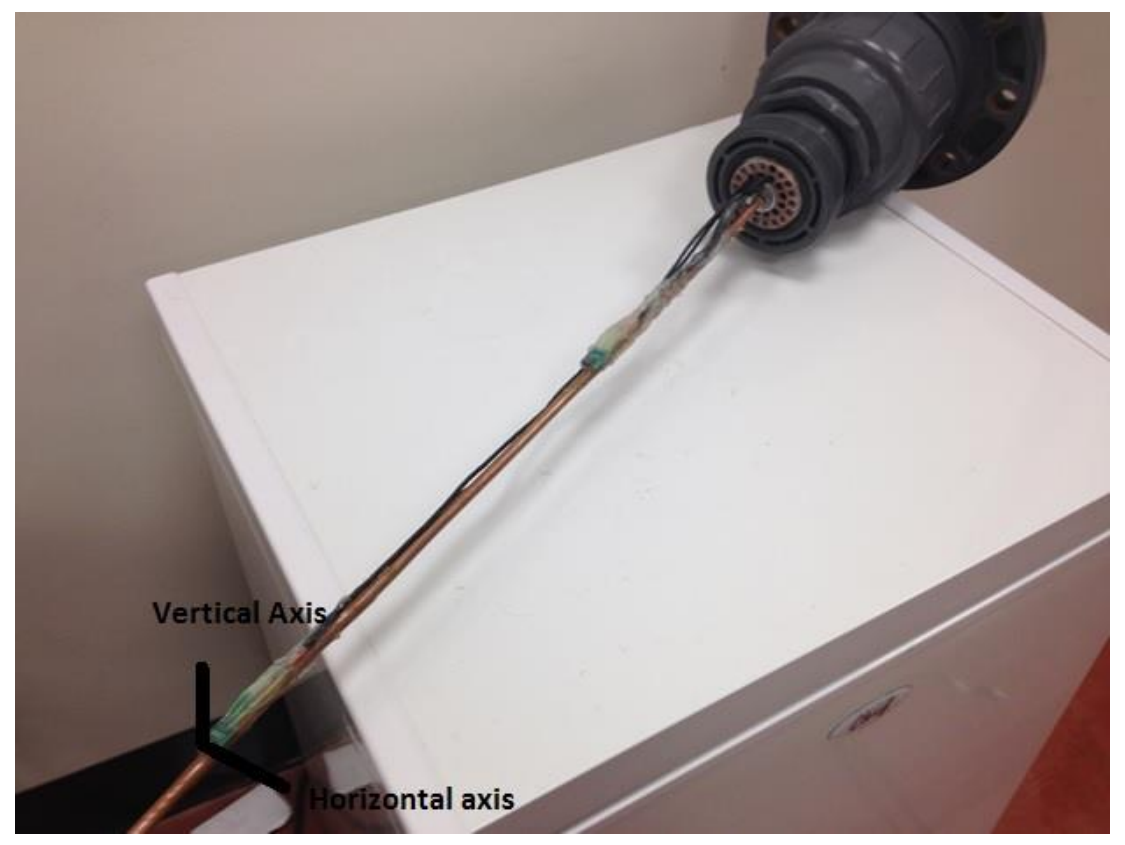

Figure 3.3: Single rod with sensors 
Two sets of sensors are mounted on the outside of the rod and covered with a silicone based sealant to prevent water from contaminating the voltage signal. These sensors are placed in two locations and each location has two sensors to measure the vertical and horizontal acceleration.

The sensors are ADXL 103 MEMS based accelerometers from Analog Devices. Each accelerometer measures acceleration in 2 axes and can measure frequencies from $0.5 \mathrm{~Hz}$ to $2000 \mathrm{~Hz}$. These specifications are important for choosing the sampling rate for the experiment and will be elaborated on in section 5.3 


\section{Chapter 4 Experimental Design}

\subsection{Sensor Locations}

The experiment is designed to produce a time signal of the acceleration of the single rod measured at two locations. The two locations chosen for the sensors were $0.25 \mathrm{~L}$ and $0.625 \mathrm{~L}$ with the origin at the "clamped" end. These positions were determined using the mode shapes for a clamped/free Euler-Bernoulli beam. A program was written in MATLAB R2013b, produced by The MathWorks Inc. referred hereafter as MATLAB, to plot the first five mode shapes as a function of fractions of $L$ with the origin at the clamped end. The mode shapes do not cross the $x$ axis at $0.25 \mathrm{~L}$ or $0.625 \mathrm{~L}$ and therefore placing the sensors at these two locations the first 5 modes can be captured. Figure 4.1 below shows the 5 mode shapes:

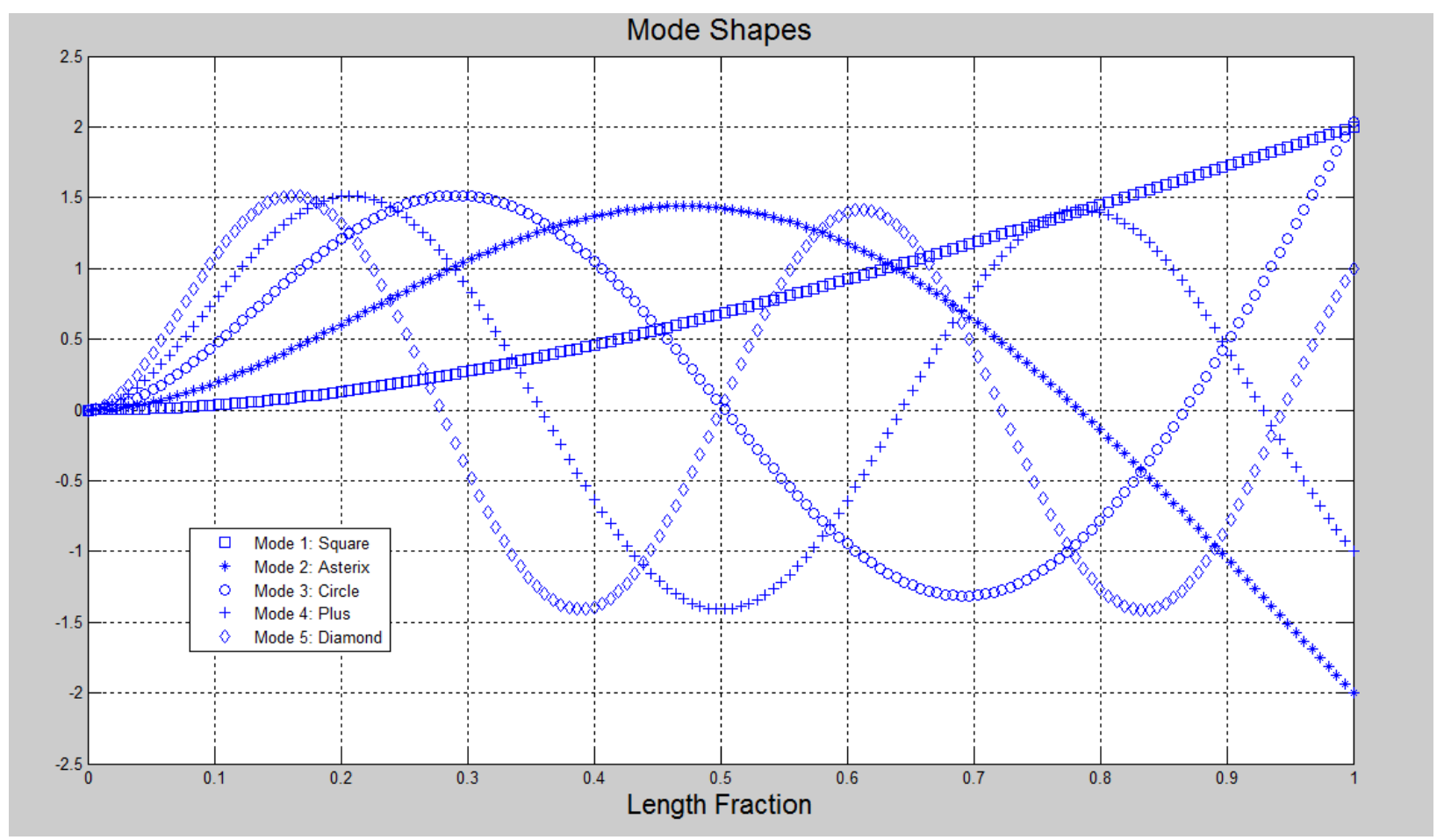

Figure 4.1: Mode shapes produced by MATLAB 
In addition to the ability of the sensors to detect the vibration modes, the location of the sensors was also important because of the flow separation induced by the blunt end of the rod. It was important to establish that the flow, if separated, would rejoin the rod after encountering the blunt tip of the rod but before the location of the tip sensors. Experimental work done by Higuchi et al (2006) established that the flow would rejoin at a distance of 1.5 times the diameter of the cylinder [10]. This means that the flow would rejoin the cylinder well before reaching the sensors so their locations will not interfere with the fluid behaviour at the tip.

\subsection{Pump Shaft Speed and Mass Flow Rate}

The mass flow rates chosen for the experiment are based on the clamped support and its interaction with the moving fluid. Above $13.4 \mathrm{~m}^{3} / \mathrm{hr}$, audible flow disturbances can be heard at the clamped support. To eliminate this effect, the flow rates were kept between 6.41 and $13.4 \mathrm{~m}^{3} / \mathrm{hr}$ which corresponds to 0.843 and $3.79 \mathrm{~kg} / \mathrm{s}$, as shown in Table 4.1 .

The pump's controller provides incremental power control and uses voltage frequency $\mathrm{Hz}$ as its unit. The pump is capable of running from 0 to $60 \mathrm{~Hz}$ voltage frequency. From this reading it is possible to estimate the motor shaft speed and therefore the vane passing frequency of this pump. For this experiment, the voltage frequency was kept between 15 and $30 \mathrm{~Hz}$, with measurements taken at every $3 \mathrm{~Hz}$ decrease starting from $30 \mathrm{~Hz}$. To provide a more 
accurate measurement of the shaft rotation speed, an optical tachometer was used to measure the rpms at each of the voltage frequency used.

Table 4.1 shows the shaft speed calculated from the tachometer readings as well as the mass flow rates from the flow meter at the corresponding controller speeds:

Table 4.1: Controller speeds, shaft rotation frequencies, and mass flow rates

\begin{tabular}{|c|c|c|}
\hline Controller speed (Hz) & Shaft rotation frequency (Hz) & Mass flow rate (kg/s) \\
\hline 30 & 13.4 & 3.79 \\
\hline 27 & 12.0 & 3.19 \\
\hline 24 & 10.6 & 2.45 \\
\hline 21 & 9.25 & 1.85 \\
\hline 18 & 7.85 & 1.34 \\
\hline 15 & 6.41 & 0.843 \\
\hline
\end{tabular}




\section{Chapter 5 Data Acquisition}

\subsection{Sensor Calibration}

The sensors were calibrated using gravity to determine the relationship between gravitational acceleration and the sensors' measured voltage. To accomplish this, the sensor was placed on a solid copper rod in a vice using an optical level to ensure, as close as possible, that the rod was level in both the longitudinal and transverse directions. The voltage was measured in 3 positions: sensor at "neutral" position with the plane of the circuit board parallel with the earth, the sensor's Y-axis pointing towards earth, and the sensor's X-axis pointing towards earth. The voltage was measured at each one of these positions over a time period of several seconds. The RMS value of the entire data set for each of the 3 positions was calculated and the differences between these RMS values gave the voltage relationship for $1 \mathrm{~g}$ gravity. A voltage of 1.12 volts was determined to be equal to $1 \mathrm{~g}$ gravity. The three positions used in the calibration are shown in appendix 4.

\subsection{Data Acquisition System}

The sensors transmit data as a voltage through the wires to a junction box. This junction box then relays the voltage data to a 4 channel oscilloscope. From the oscilloscope the data is transmitted to a laptop computer. A program called TiePie, produced by TiePie engineering, was used to display and capture the data. 


\subsection{Sampling Theorem}

A 16 bit resolution was used to ensure the smoothness of the data stream, meaning that the data stream is broken up $2^{16}$ pieces. To capture the low frequency motions observed a sufficient time period was needed to be recorded. This was achieved using a combination of sample size and sampling rate which provided a 6.71 second long data set. This sample length was arrived at by using the largest sample size possible in the TiePie software, 131,073 data points, and a $20 \mathrm{kHz}$ sampling frequency.

A sampling rate of $20 \mathrm{kHz}$ was chosen based on the sensing range of the sensors used, which in this case is $2000 \mathrm{~Hz}$ along with the Nyquist sampling theorem. The theorem states that the sampling frequency must be at least twice that of the highest frequency contained in the signal [11]. The minimum sampling frequency based on this theorem is $4 \mathrm{kHz}$. The chosen sampling rate is $20 \mathrm{kHz}$ or 10 times the sensing range of the sensors. $20 \mathrm{kHz}$ was chosen because the settings on the TiePie program only have distinct values of sampling frequency and the next lowest sampling frequency was less than $8 \mathrm{kHz}$. Even though this would pass the test of the sampling theorem, this sampling rate and number of data points combination would give a 16 second signal. This signal length was deemed to be excessive and not necessary. The next setting higher was $20 \mathrm{kHz}$ which provides a 6.71 second signal. This signal length was decided to be sufficient to capture the observed low frequency phenomena. This sampling rate provided both reliability in capturing the signal and accurate representation of the captured signal. 


\section{Chapter 6 Results}

\subsection{Determining Natural Frequencies}

In order to determine the bending natural frequencies of the rod the whole assembly was excited by an impact with a rubber mallet. As the rod is assumed to be axisymmetric and circular, the natural frequencies in one axis are assumed to be the same as any other axis.

Using a program written in the software MATLAB, shown in Appendix 3, the raw data was first read into the MATLAB program from a CSV or comma spaced value file produced by TiePie. Using the mean function in MATLAB the mean value of the voltage was calculated and then the voltage difference for each time increment was calculated:

$$
V_{\text {Difference }}=V_{i}-V_{\text {mean }}
$$

This voltage difference was transformed from a voltage to acceleration in terms of gravitational acceleration g:

$$
g=\frac{V_{\text {Difference }}}{1.12}
$$

Figures 6.1 and 6.2 below show the excitation signals gathered from the natural frequency tests performed when the test chamber was filled with air and when it was filled with water: 


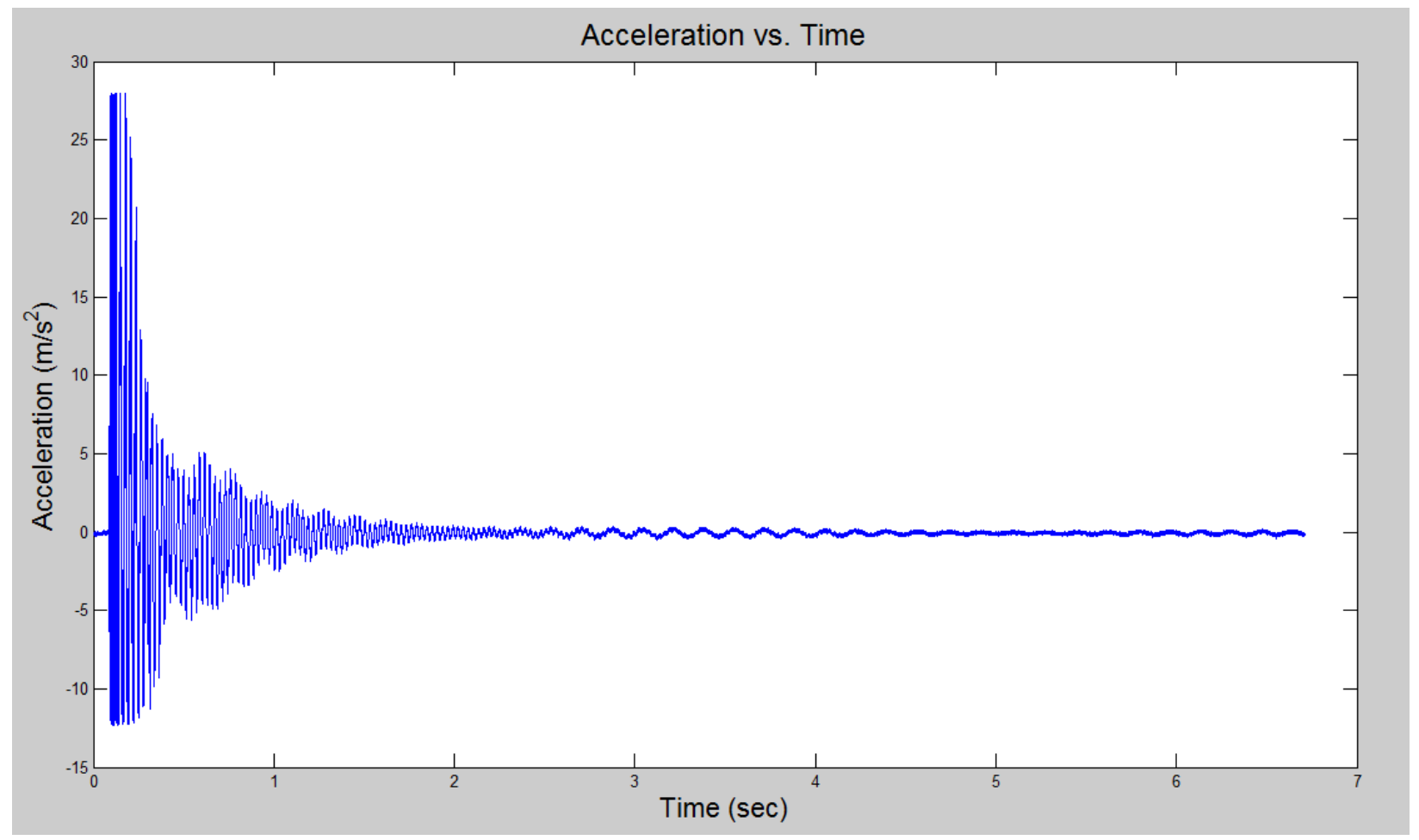

Figure 6.1: Acceleration vs. time signal of impact excitation in air in vertical direction

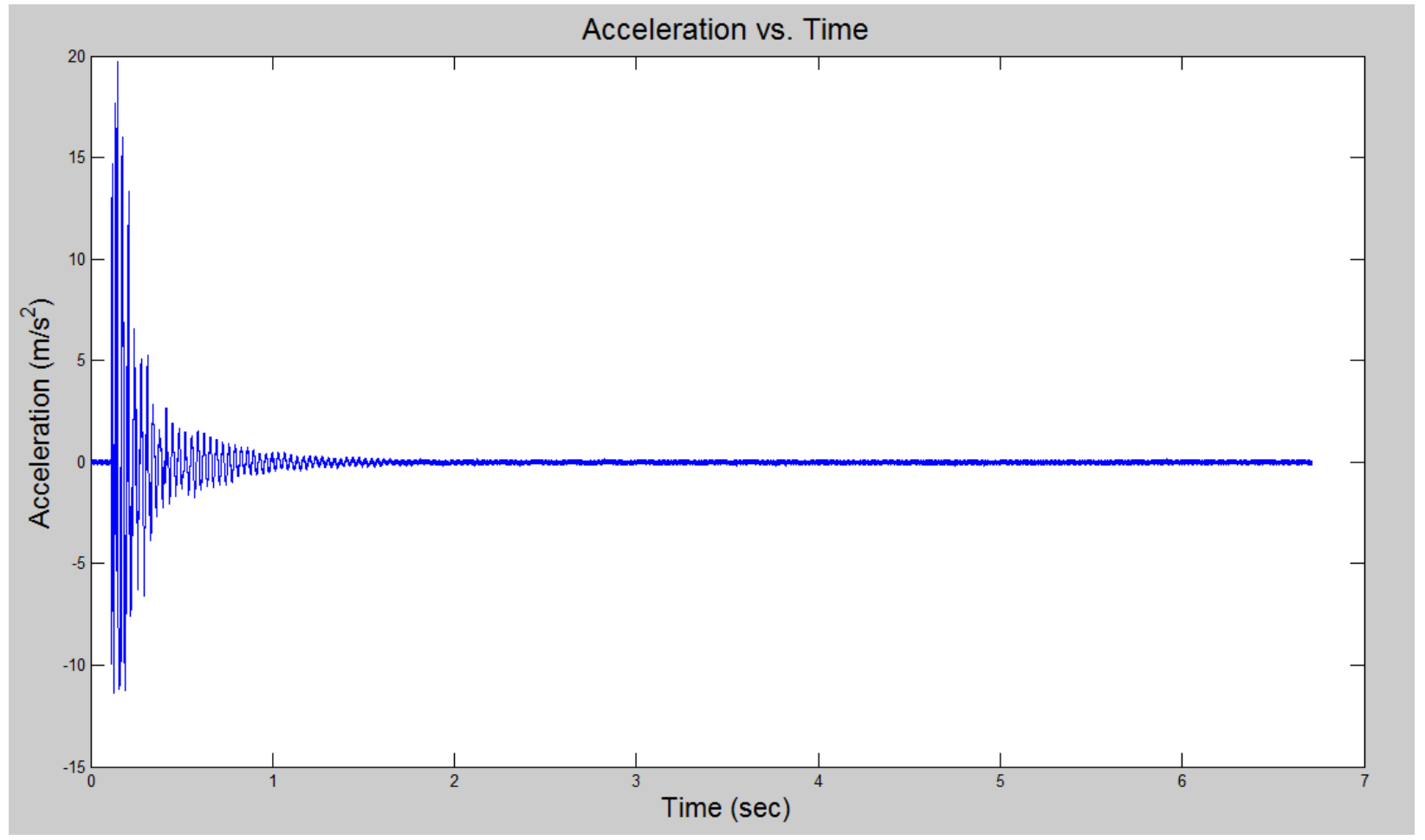

Figure 6.2: Acceleration vs. time signal of impact excitation in water in vertical direction 
In order to see what frequencies are present in the signal it is necessary to produce a power spectrum density graph of the measured data. To create the power spectrum density of the acceleration data provided above the cross power spectrum function in MATLAB was used. Figures 6.3 and 6.4 show the resulting power spectrum densities for the excitation tests in air and water respectively:

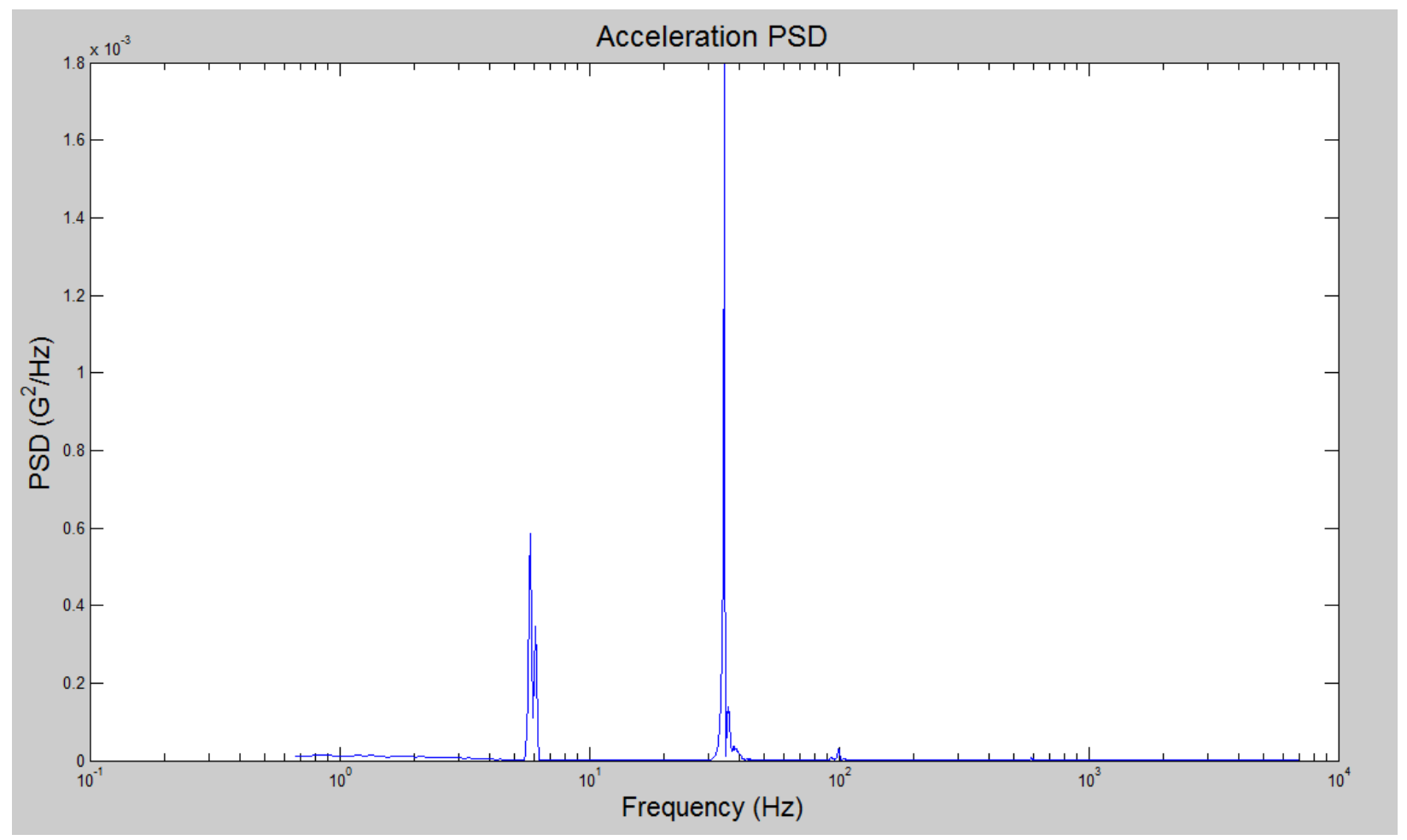

Figure 6.3: Acceleration power spectrum density from impact air test 


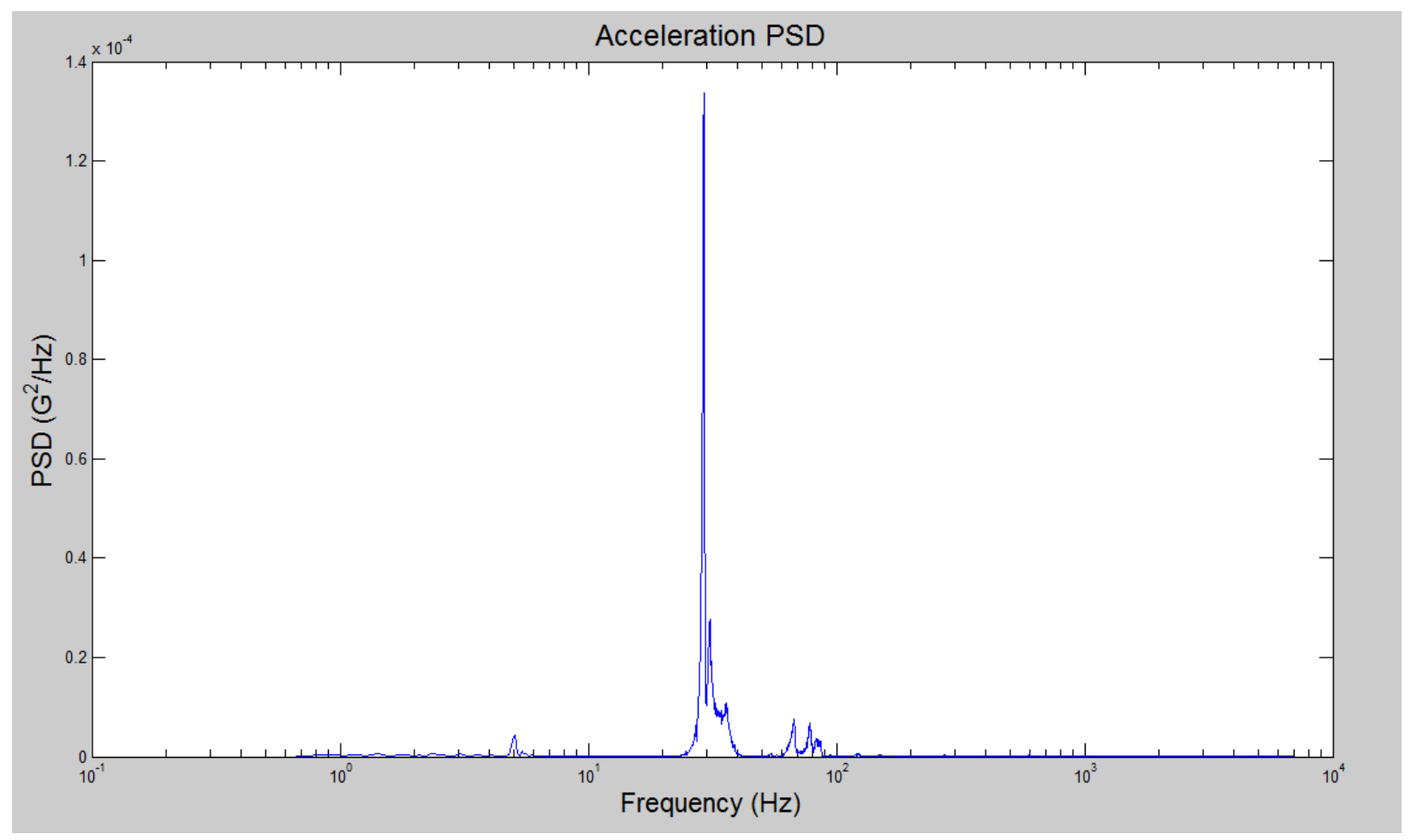

Figure 6.4: Acceleration power spectrum density from impact water test

To make the data more relatable to the phenomena observed by the eye it was necessary to transform the acceleration power spectrum density into a displacement power spectrum density. This was done using the following equation [12]:

$$
D P S D=A P S D / \omega^{4} * 9.81^{4}
$$

The displacement power spectrum density needed to be in a unit of $\mathrm{m}^{2} / \mathrm{Hz}$. To accomplish this the acceleration power spectrum density value must be multiplied by $9.81^{4}$, given that the units of the acceleration power spectrum density are in $G^{2} / \mathrm{Hz}$. This calculation has the effect of accentuating the amplitudes of the lower frequencies while diminishing the 
amplitudes of the higher frequencies. For this reason no frequency below $1 \mathrm{~Hz}$ was plotted in the displacement power spectrum densities. The displacement power spectrum densities will allow for the quantification of the observable low frequencies while the system is excited by a moving fluid. Figures 6.5 and 6.6 shown below are the transformations of the two acceleration power spectrum densities of the air and water tests respectively:

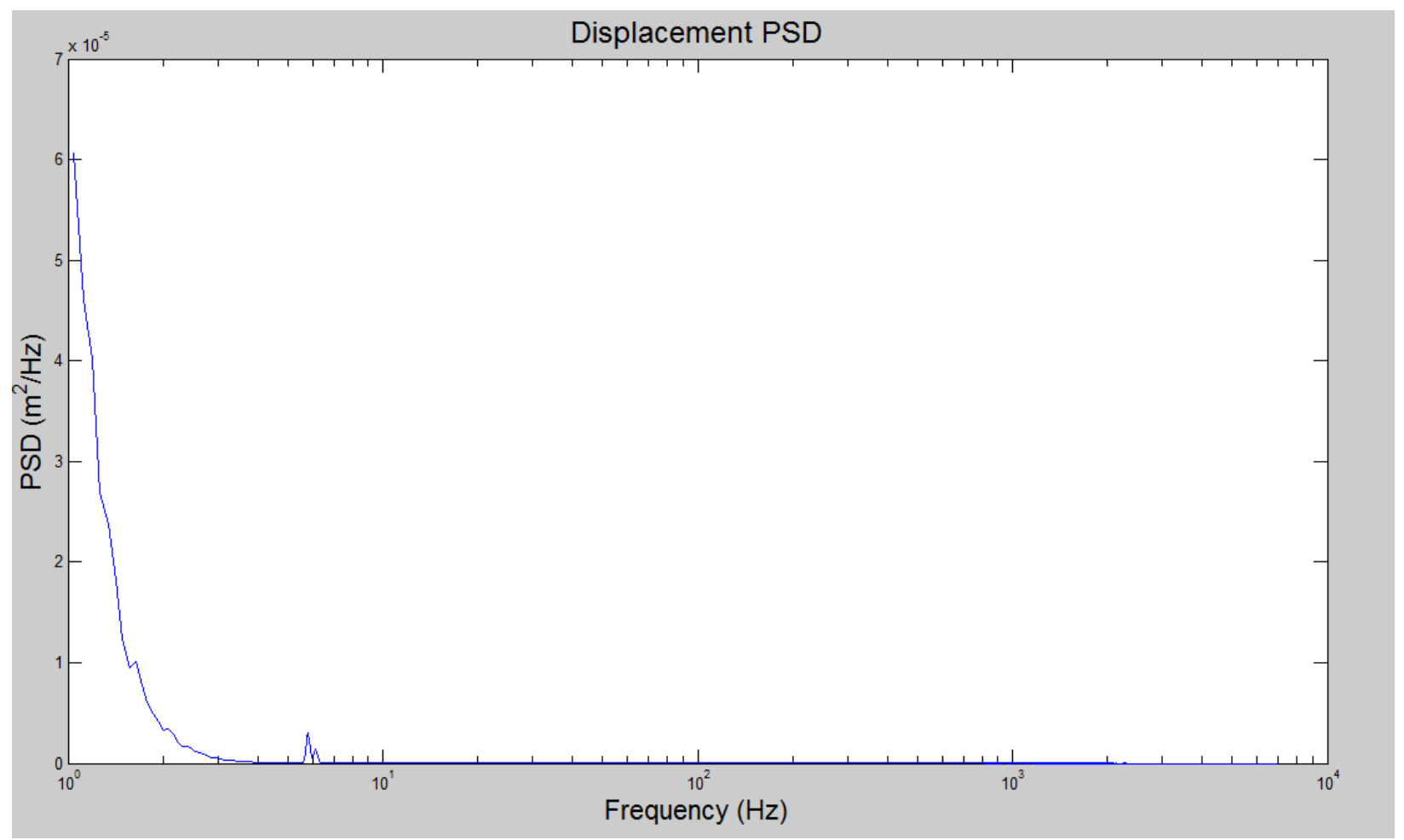

Figure 6.5: Displacement power spectrum density from impact air test 


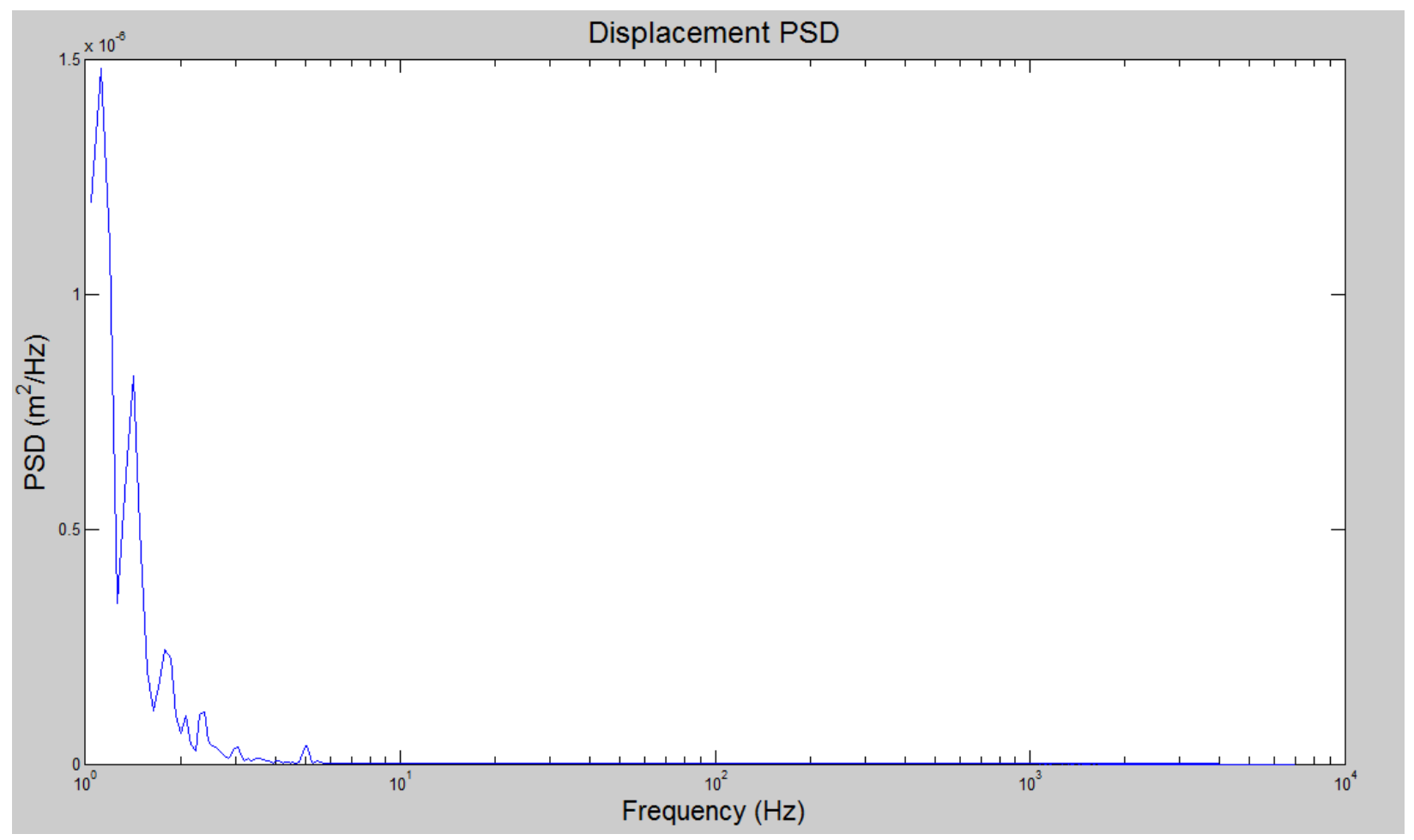

Figure 6.6: Displacement power spectrum density from impact water test

As can be observed from the acceleration power spectrum charts above the quiescent fluid around the rod adds a damping effect to the system for all frequencies since the amplitudes in the water impact test are 2 orders of magnitude smaller than the air test. Table 6.1 below shows the calculated first mode natural frequency of a clamped-free Euler-Bernoulli beam compared with the measured frequencies from the displacement power spectrum density. The Euler-Bernoulli natural frequency was calculated using equation 6.3 and constants shown below [13]. Comparing the two measured non-classical frequencies with each other, we can see the effect of the added mass of the still water surrounding the beam:

$$
\begin{gathered}
\omega_{n}=\beta_{n}{ }^{2} \sqrt{E I / \rho A} \\
\beta_{1} l=1.875
\end{gathered}
$$


Table 6.1: Calculated natural frequency vs. measured frequencies in power spectrum

\begin{tabular}{|c|c|c|}
\hline $\begin{array}{c}\text { Calculated (Hz) } \\
\text { (Classical fixed/free } \\
\text { boundary condition, no } \\
\text { damping) }\end{array}$ & $\begin{array}{c}\text { Measured Air (Hz) } \\
\text { (Non-classical boundary } \\
\text { condition, structural } \\
\text { damping) }\end{array}$ & $\begin{array}{c}\text { Measured Water (Hz) } \\
\text { (Non-classical boundary } \\
\text { condition, structural } \\
\text { damping) }\end{array}$ \\
\hline 7.92 & 5.81 & 4.992 \\
\hline
\end{tabular}

\subsection{Results from Flowing Fluid}

For the results shown below, the mass flow rate is kept below $3.79 \mathrm{~kg} / \mathrm{s}$ to eliminate audible flow disturbances occurring at the rod support. Figures 6.7 through 6.10 below show all the acceleration vs time graphs. Figures 6.11 and 6.12 show the composite plots with all the acceleration power spectrum densities obtained from each of the 6 different mass flow rates for both the vertical and horizontal directions:

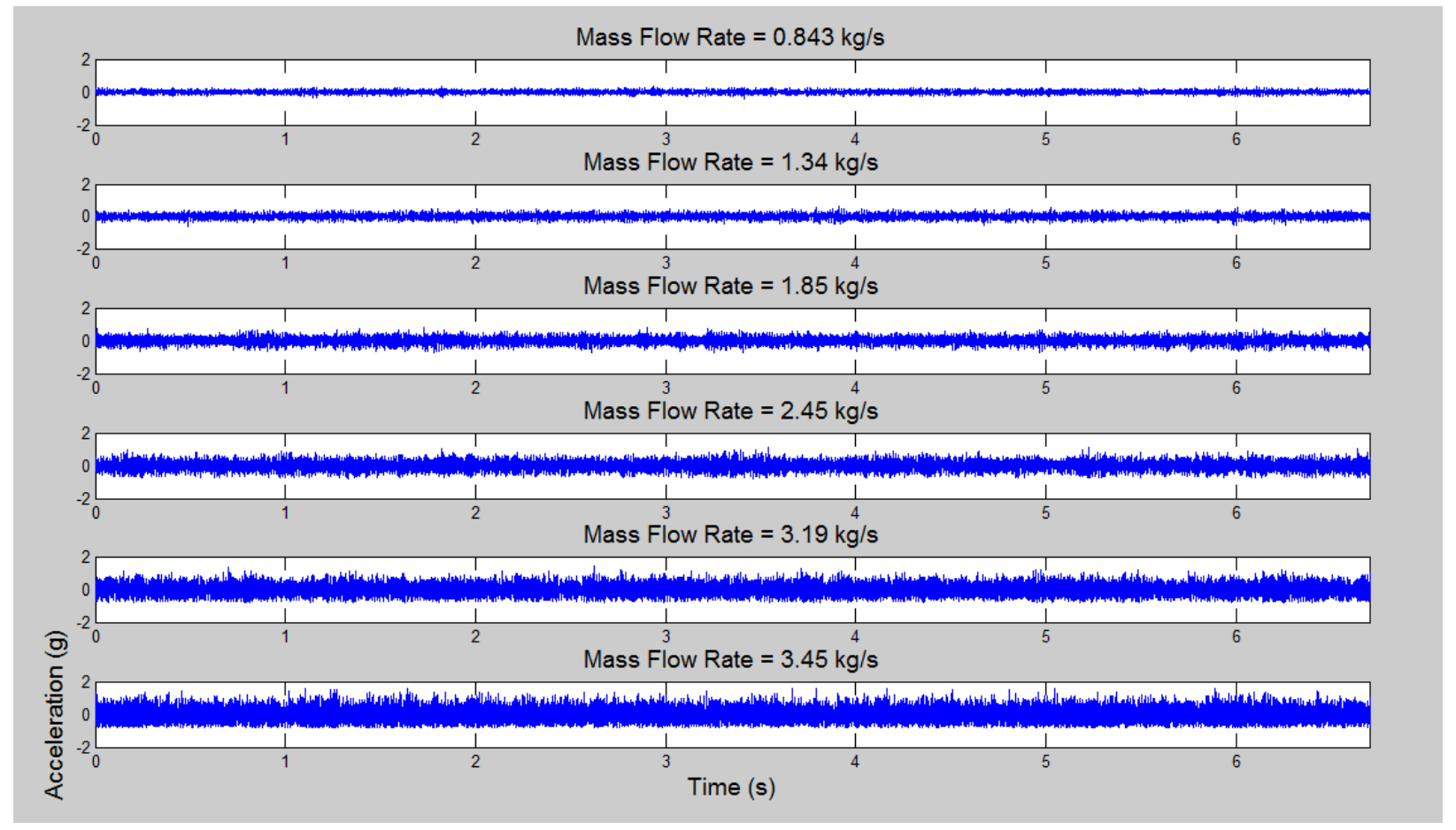

Figure 6.7: Acceleration vs time graphs for $0.625 \mathrm{~L}$ position in vertical direction 


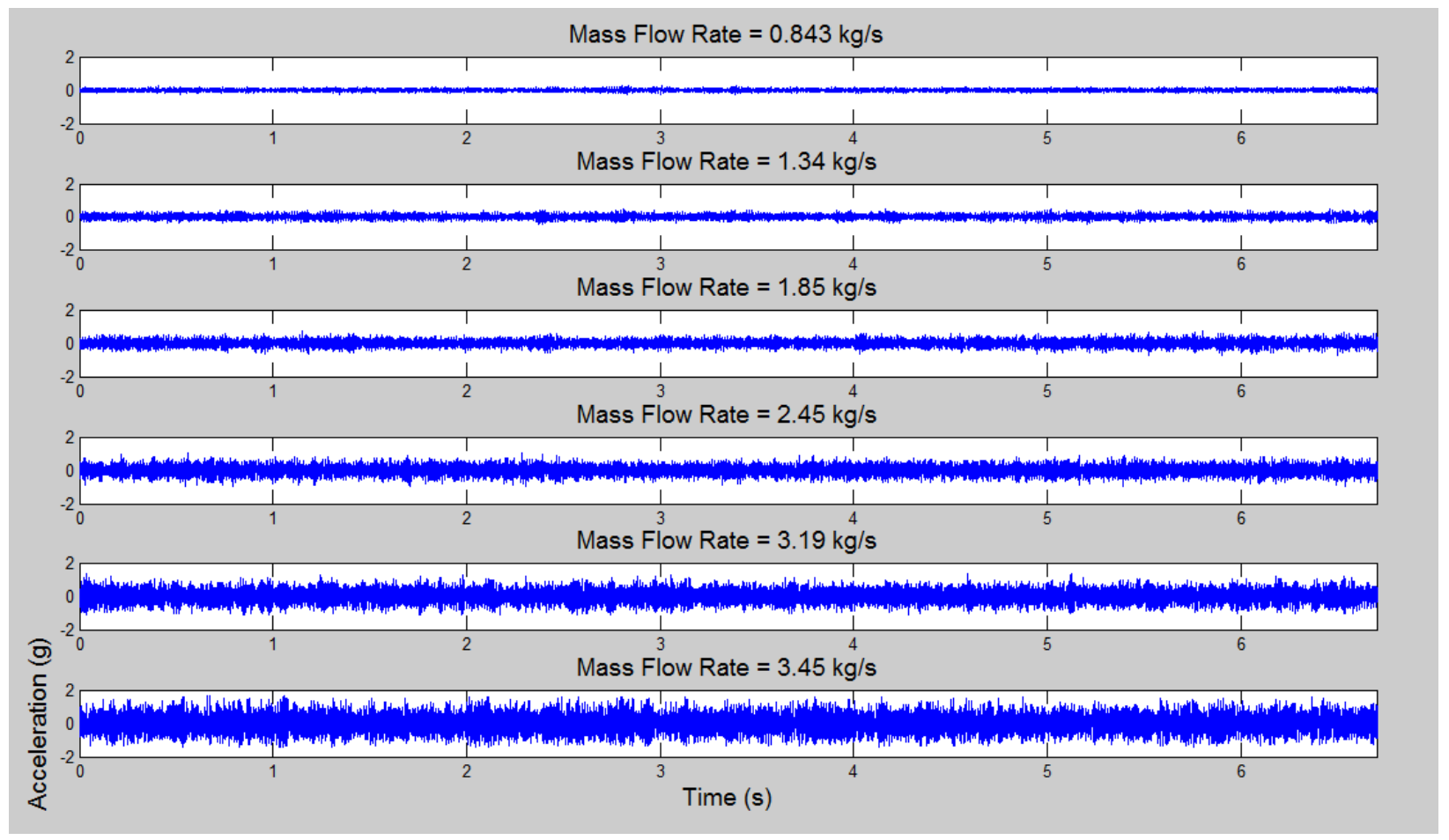

Figure 6.8: Acceleration vs time graphs for $0.625 \mathrm{~L}$ position in horizontal direction

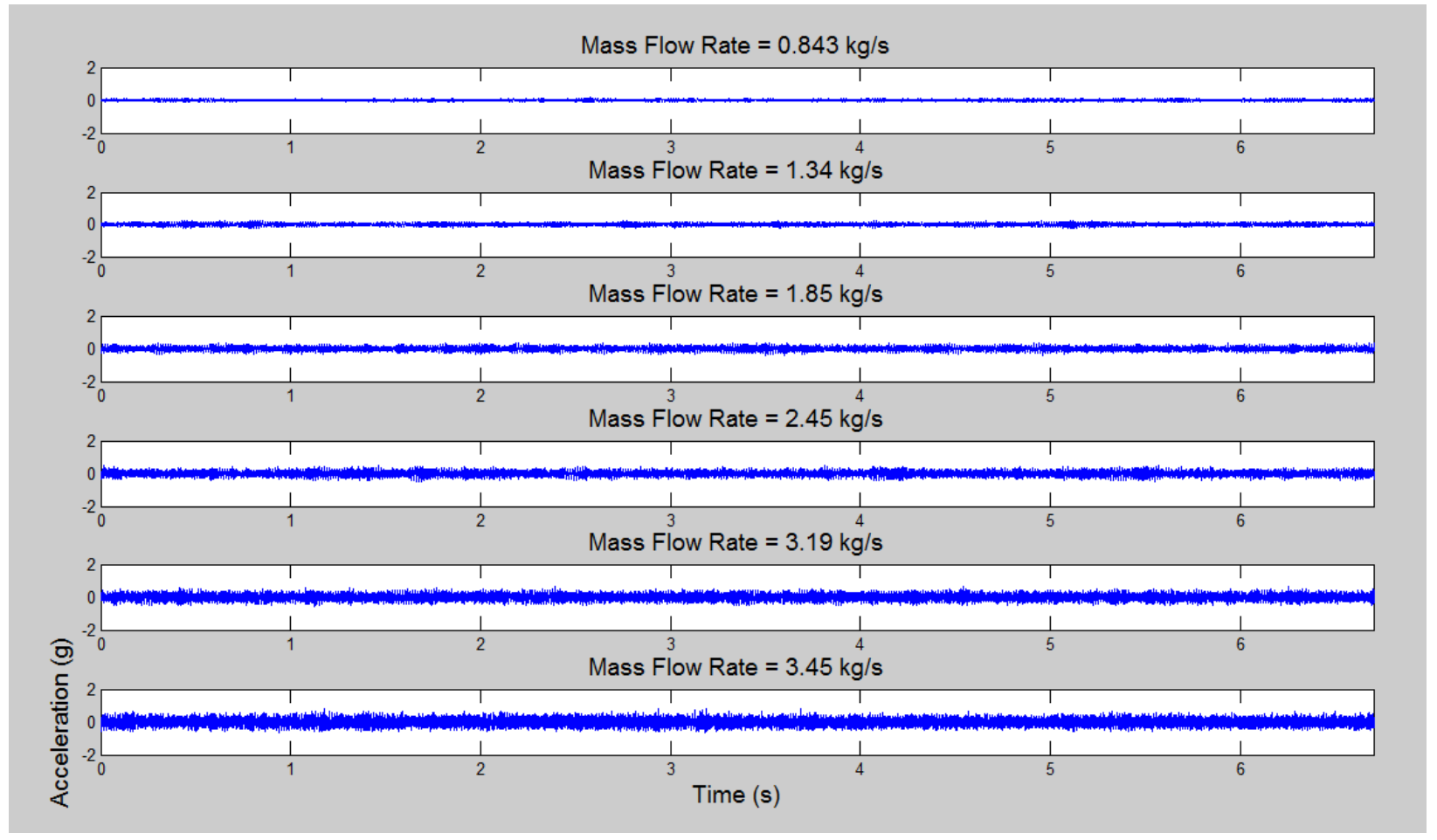

Figure 6.9: Acceleration vs time graphs for $0.25 \mathrm{~L}$ position in vertical direction 


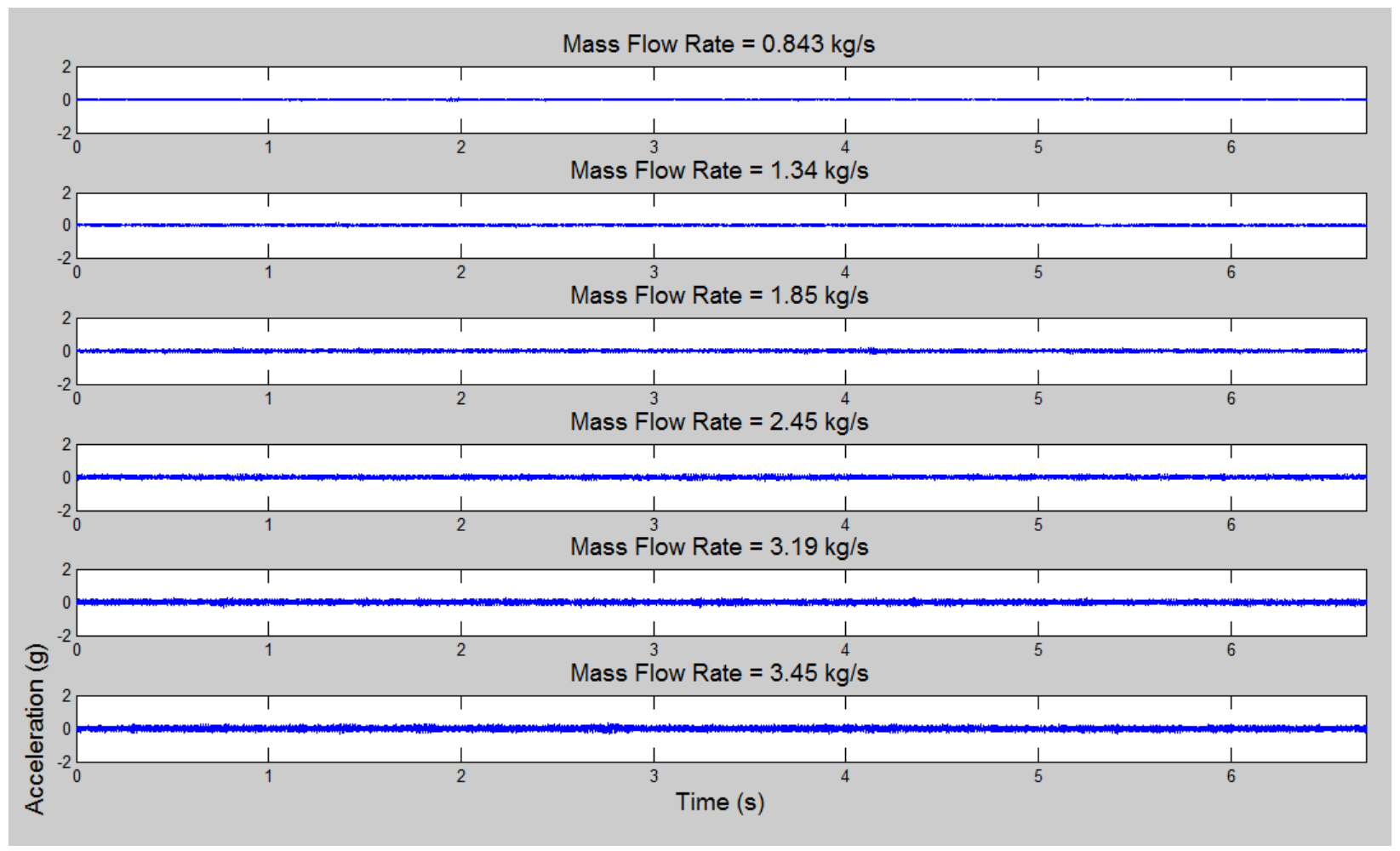

Figure 6.10: : Acceleration vs time graphs for $0.25 \mathrm{~L}$ position in horizontal direction

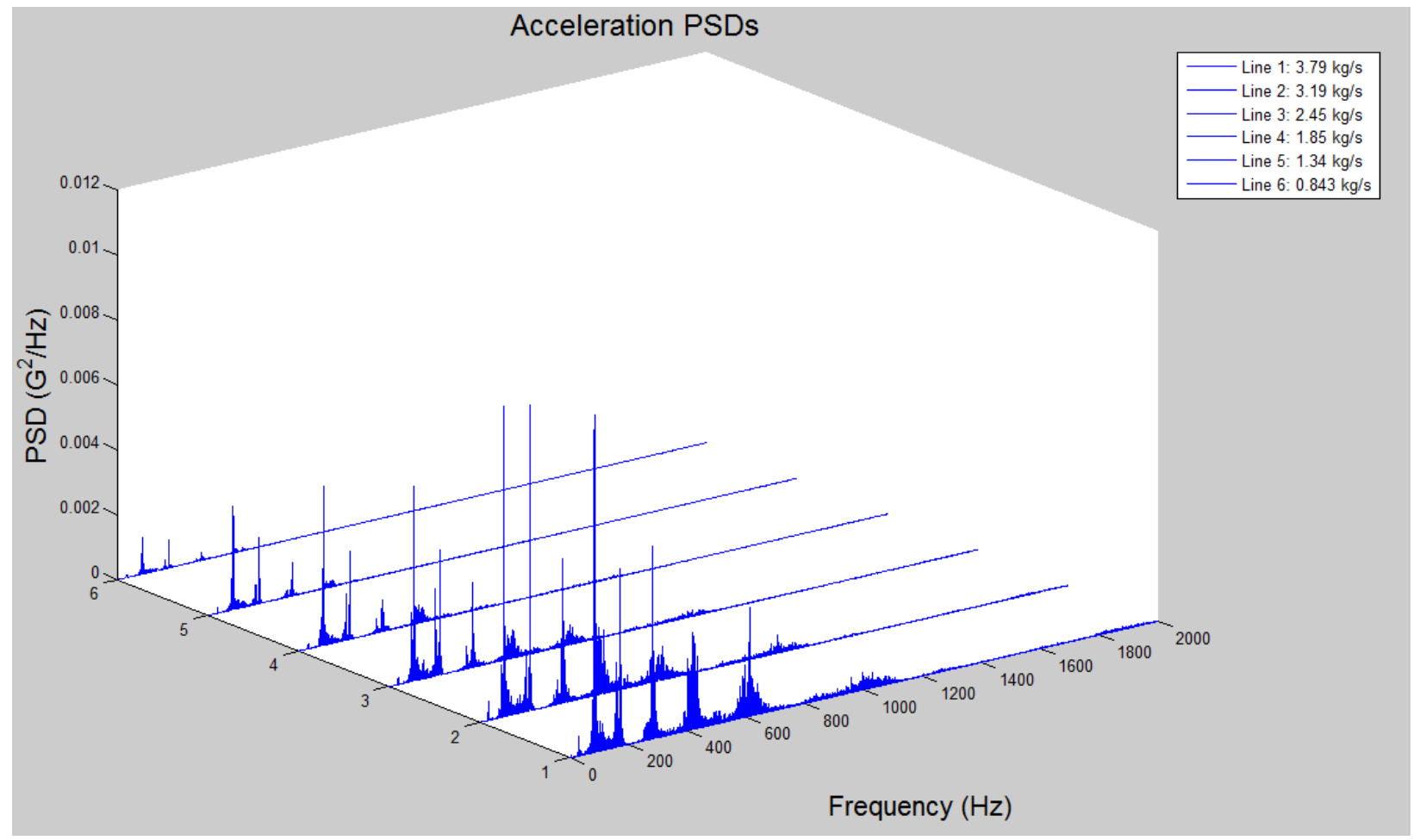


Figure 6.11: Composite acceleration power spectrum densities from $0.625 \mathrm{~L}$ in vertical direction

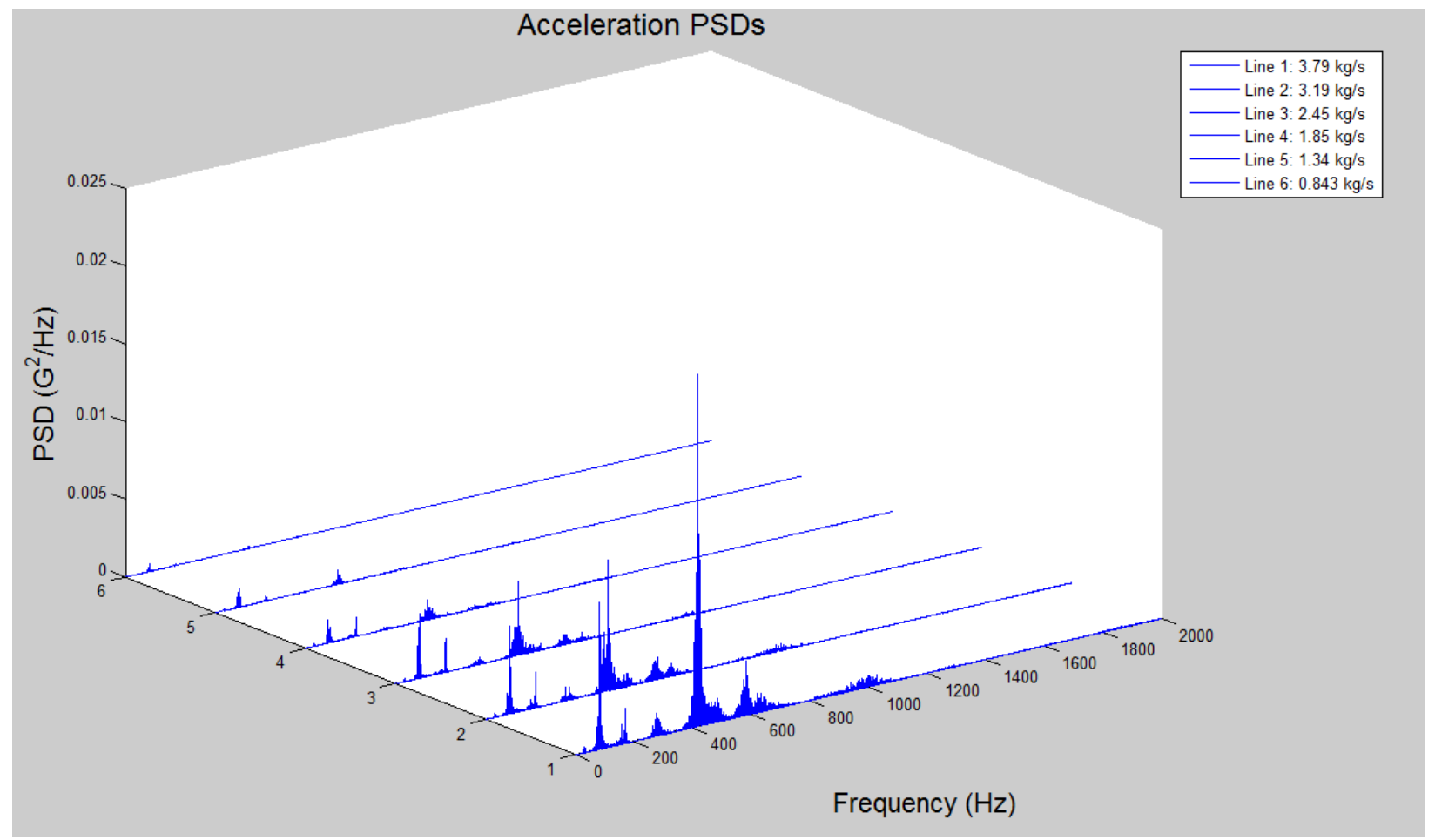

Figure 6.12: Composite acceleration power spectrum densities from $0.625 \mathrm{~L}$ horizontal direction

The acceleration power spectrum densities were transformed into displacement power spectrum densities using Equation 6.2 listed above. No frequency below $1.5 \mathrm{~Hz}$ was plotted since the calculations of frequencies create false asymptotes. Since the first mode bending frequency was calculated to be around $5 \mathrm{hz}$ this would not affect the results. The effect of the calculations is to de-emphasize the high frequencies while amplifying the lower frequencies. The displacement power spectrum densities for the same set of conditions as the acceleration plots for both the vertical and horizontal directions are displayed in figures 6.13 and 6.14: 


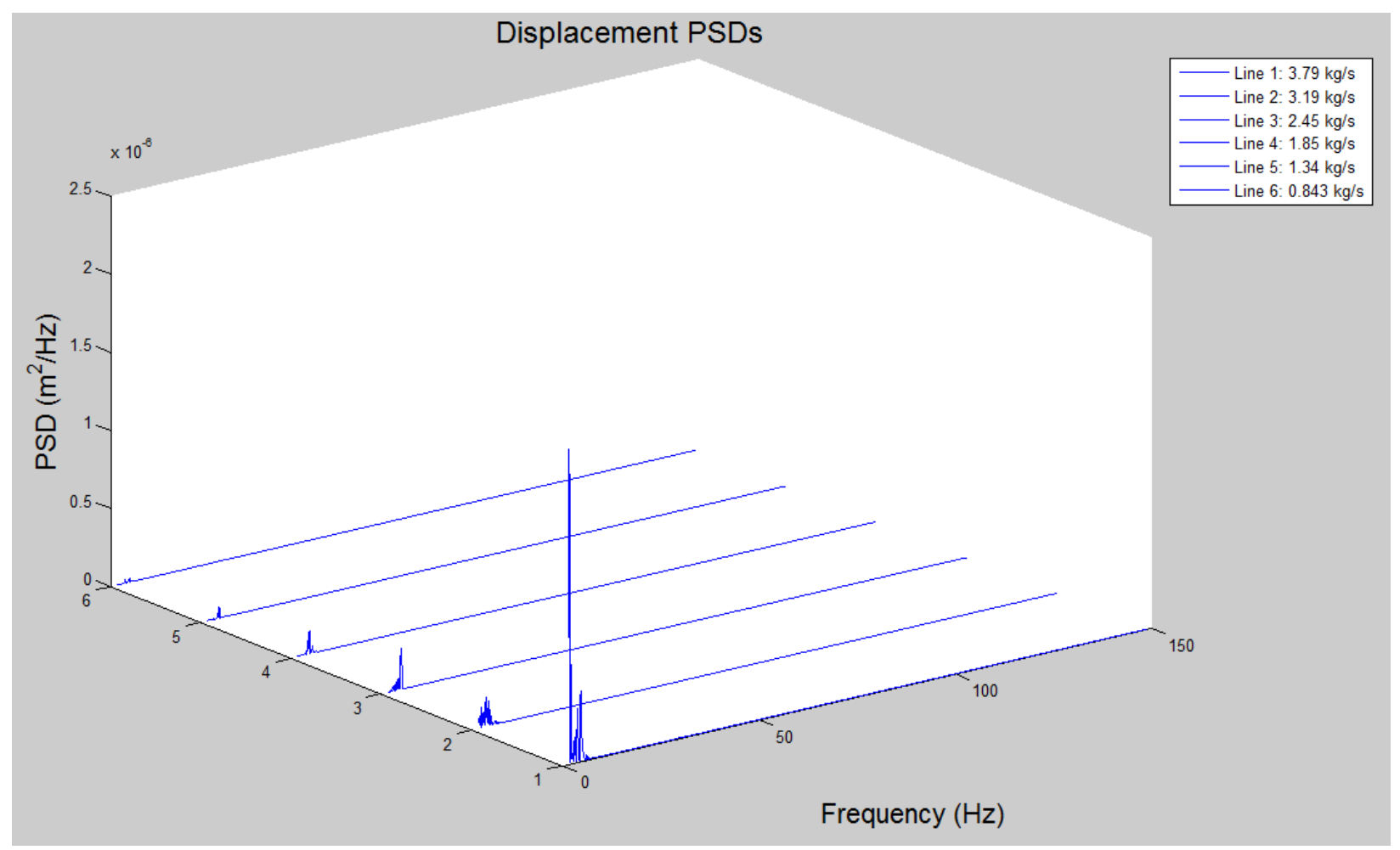

Figure 6.13: Displacement power spectrum densities computed from figure 6.7

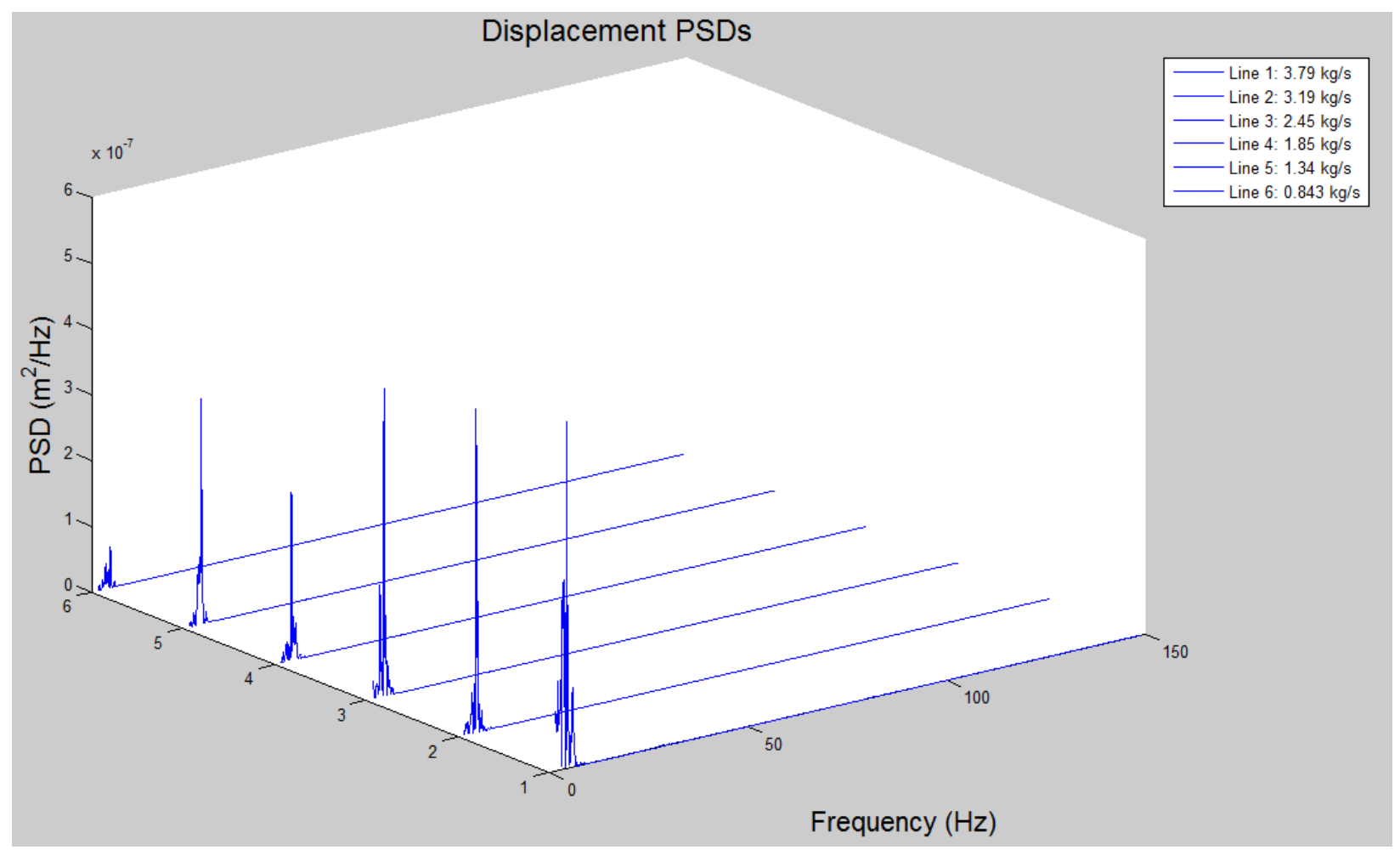

Figure 6.14: Displacement power spectrum densities computed from figure 6.8 
The effect of the diminishing of high frequencies can be seen as, for example, the displacement power spectrum values at frequencies above $10 \mathrm{~Hz}$ are of no significance. This result reflects what was observed in the experiment, as the phenomenon was of a low enough frequency that it could be observed with the unaided eye. The power spectrum densities of the displacement show that the $1^{\text {st }}$ bending mode of vibration is the dominant mode of the rod when treated as an Euler-Bernoulli beam.

This can also be seen in the data gathered from the base sensor. Figures 6.15 through 6.18 below are the composite acceleration and displacement power spectrum densities respectively for the sensors located near the base:

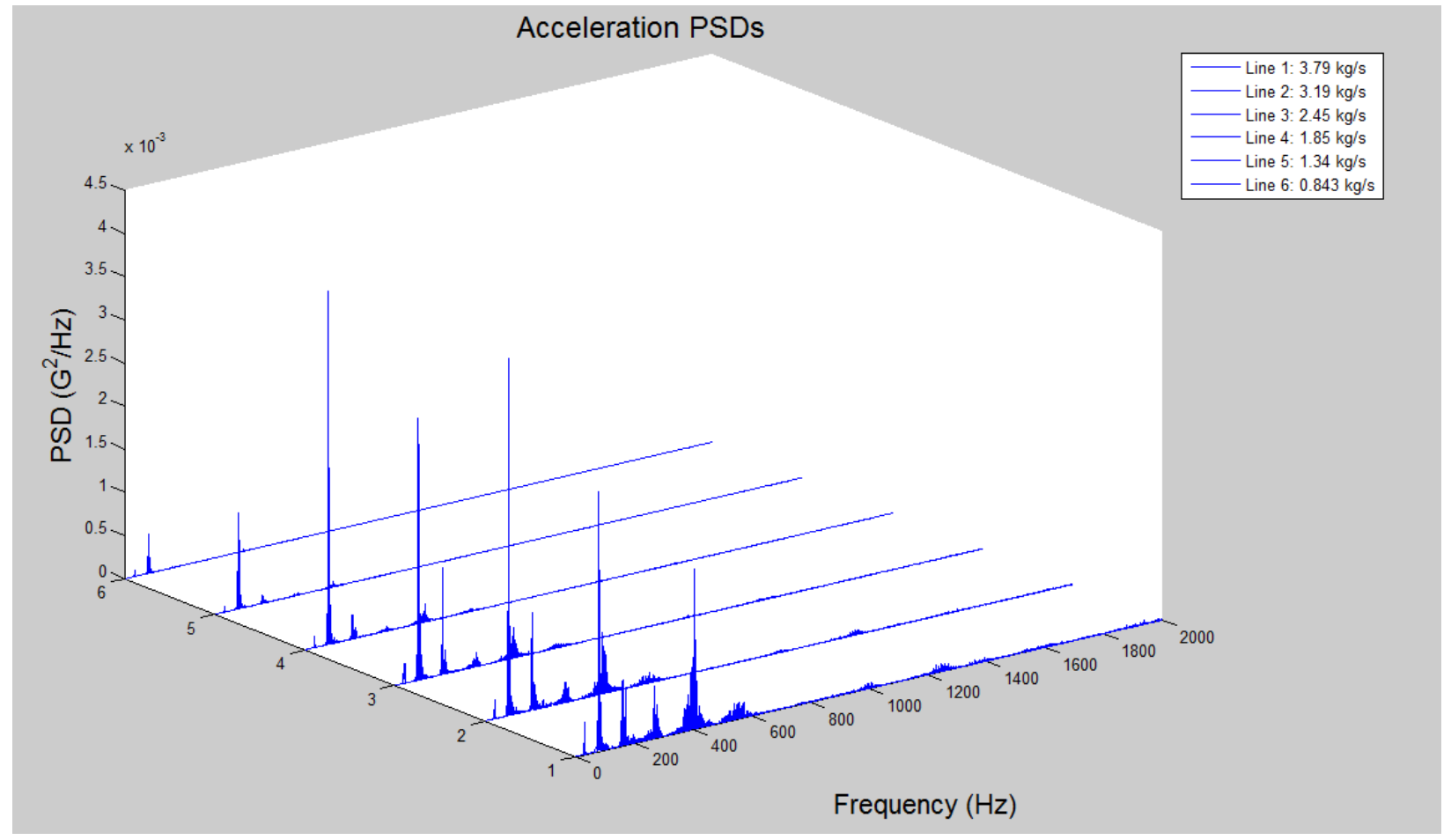

Figure 6.15: Composite acceleration power spectrum densities from $0.25 \mathrm{~L}$ in vertical direction 


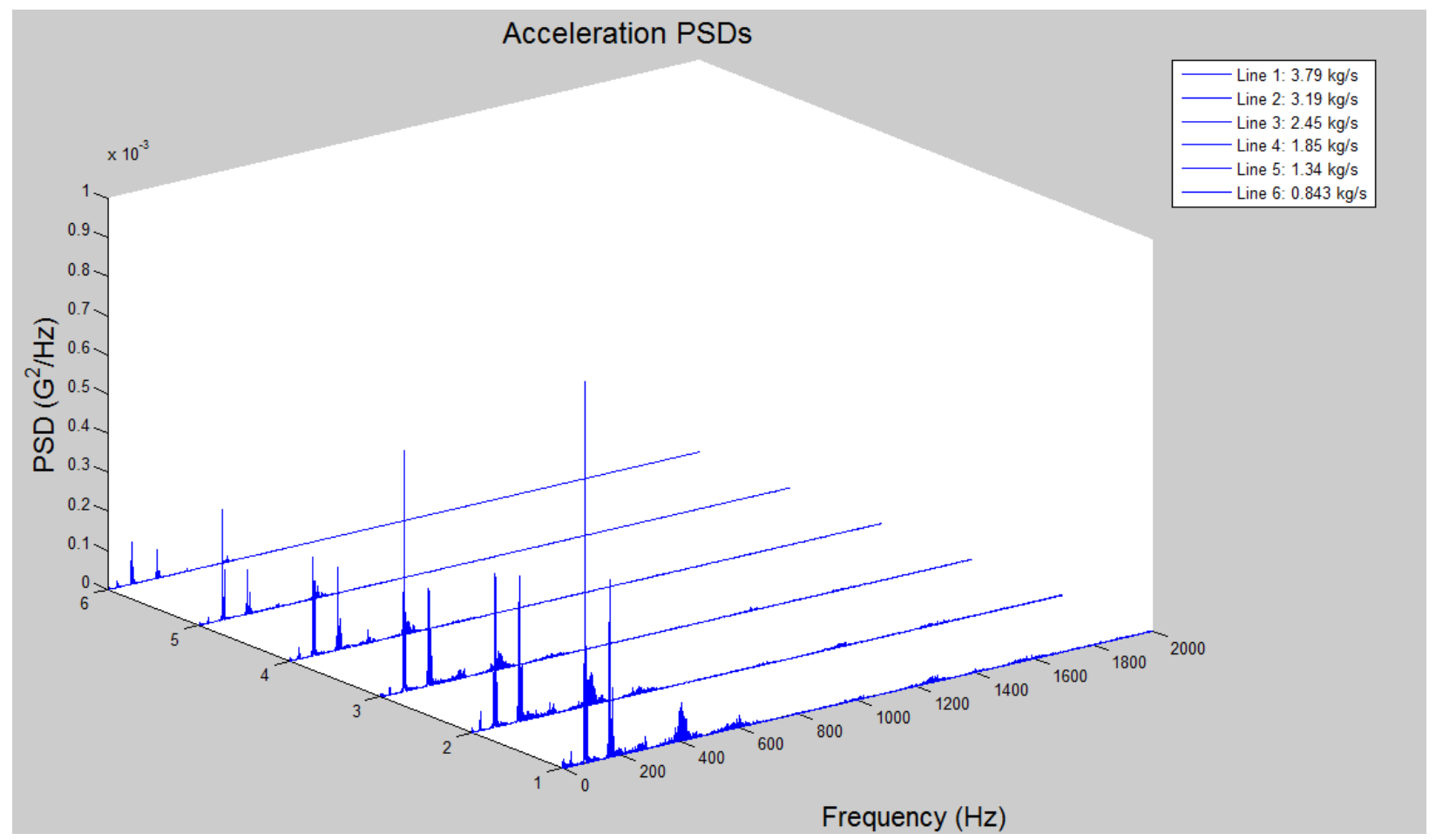

Figure 6.16: Composite acceleration power spectrum densities from $0.25 \mathrm{~L}$ in horizontal direction

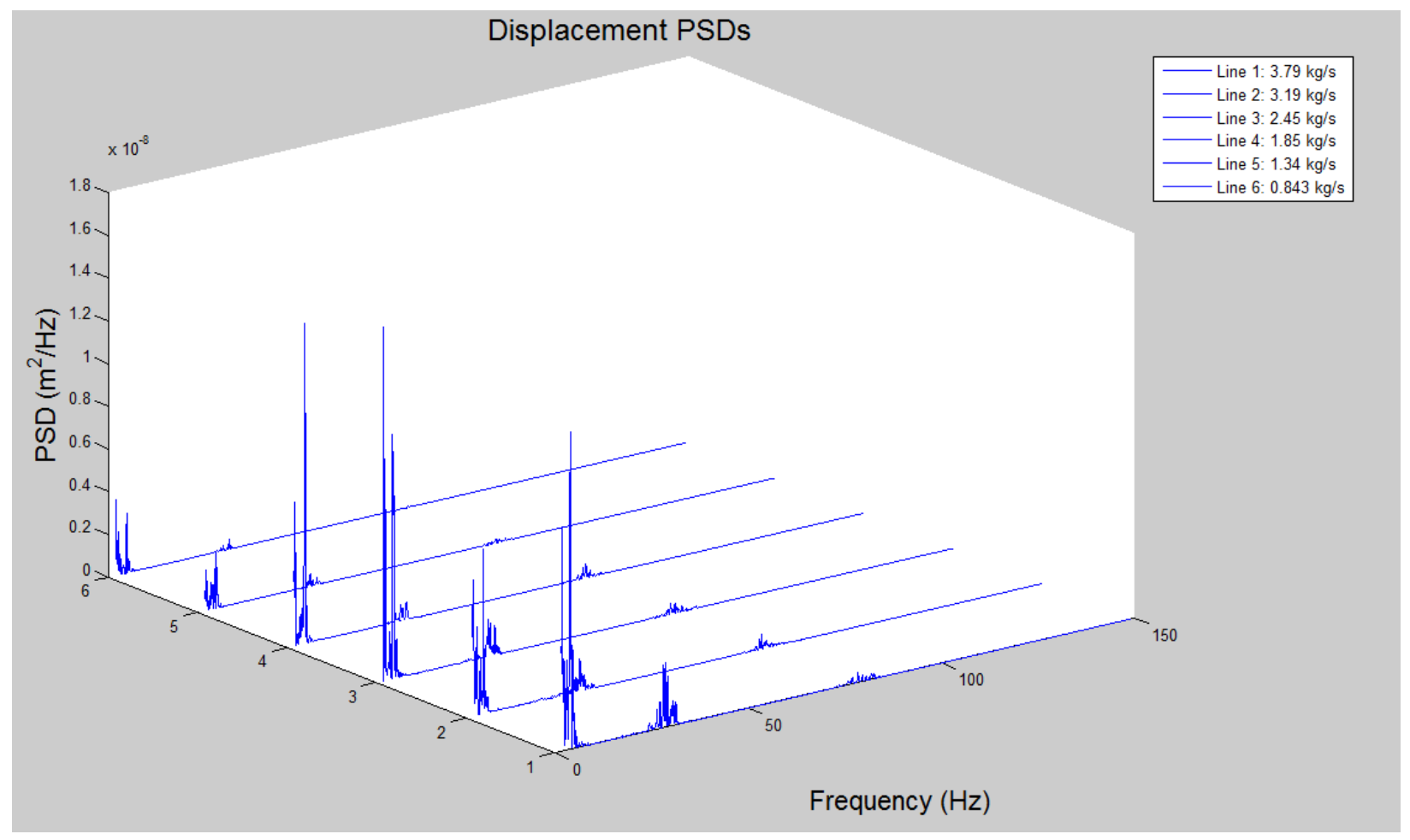

Figure 6.17: Displacement power spectrum densities calculated from figure 6.11 


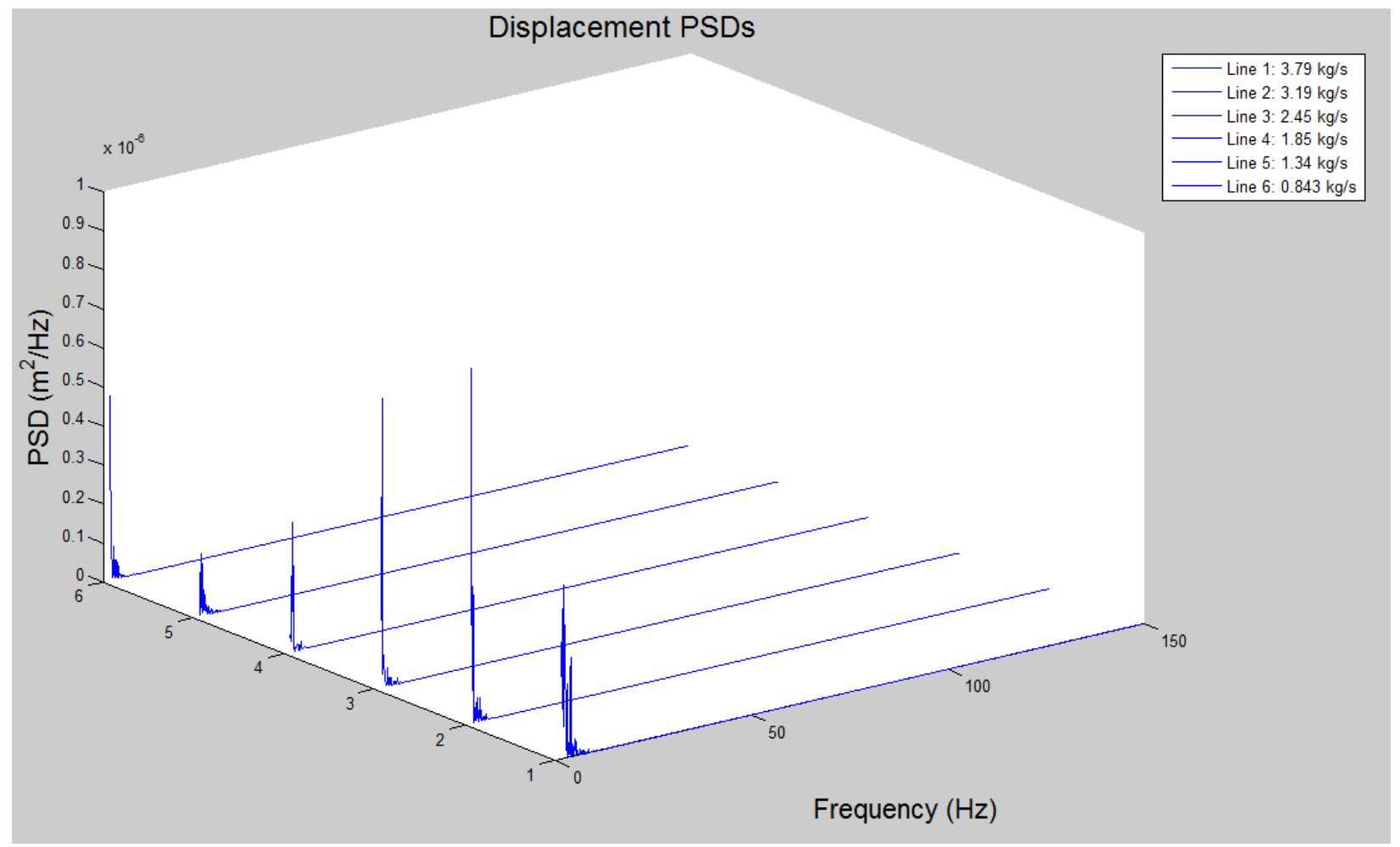

Figure 6.18: Displacement power spectrum densities calculated from figure 6.12

These plots show that more than one bending frequency is present in the measurements of the vertical direction. The first mode is the dominant mode frequency, but the second and third mode vibrations also appear in the vertical direction. While there appears not to be a definitive relationship between the mass flow rate and the energy present in each frequency, it can be seen that the first mode of bending is the dominant bending frequency measured at all mass flow rates for both the vertical and horizontal directions.

The next section will discuss the analysis and implications of the data gathered. 


\section{Chapter 7 Discussion of Results}

Since there are three possible responses of flow induced vibrations it is necessary to investigate the features of each of the three responses and determine which is/are the measured response of the observed beam vibrations.

\subsection{Fluid-Elastic Instability}

To investigate fluid-elastic instability it is necessary to calculate the dimensionless flow velocity for each of the different mass flow rates used in the experiment. Using Equation 2.1 from the literature review, the dimensionless velocity for the hollow copper rod was calculated to be between 0.045 and 0.0965 . Figures 7.1 and 7.2 below show the relationship between the dimension displacement of the rod and the dimensionless flow velocity in both the vertical and horizontal directions from the tip sensors. Figures 7.3 and 7.4 show the relationships between the dimension displacements of the rod and the dimensionless flow velocities in both the vertical and horizontal directions from the base sensors. The formula used to calculate the dimensionless displacement is given below [1]:

$$
\eta=\frac{\text { amplitude }_{r m s}}{d_{\text {rod }}}
$$

The root mean square amplitude is found by first taking the integral of the power spectrum density and then taking the square root of that value [14]:

$$
\text { amplitude }_{r m s}=\sqrt{\int D P S D(f) d f}
$$




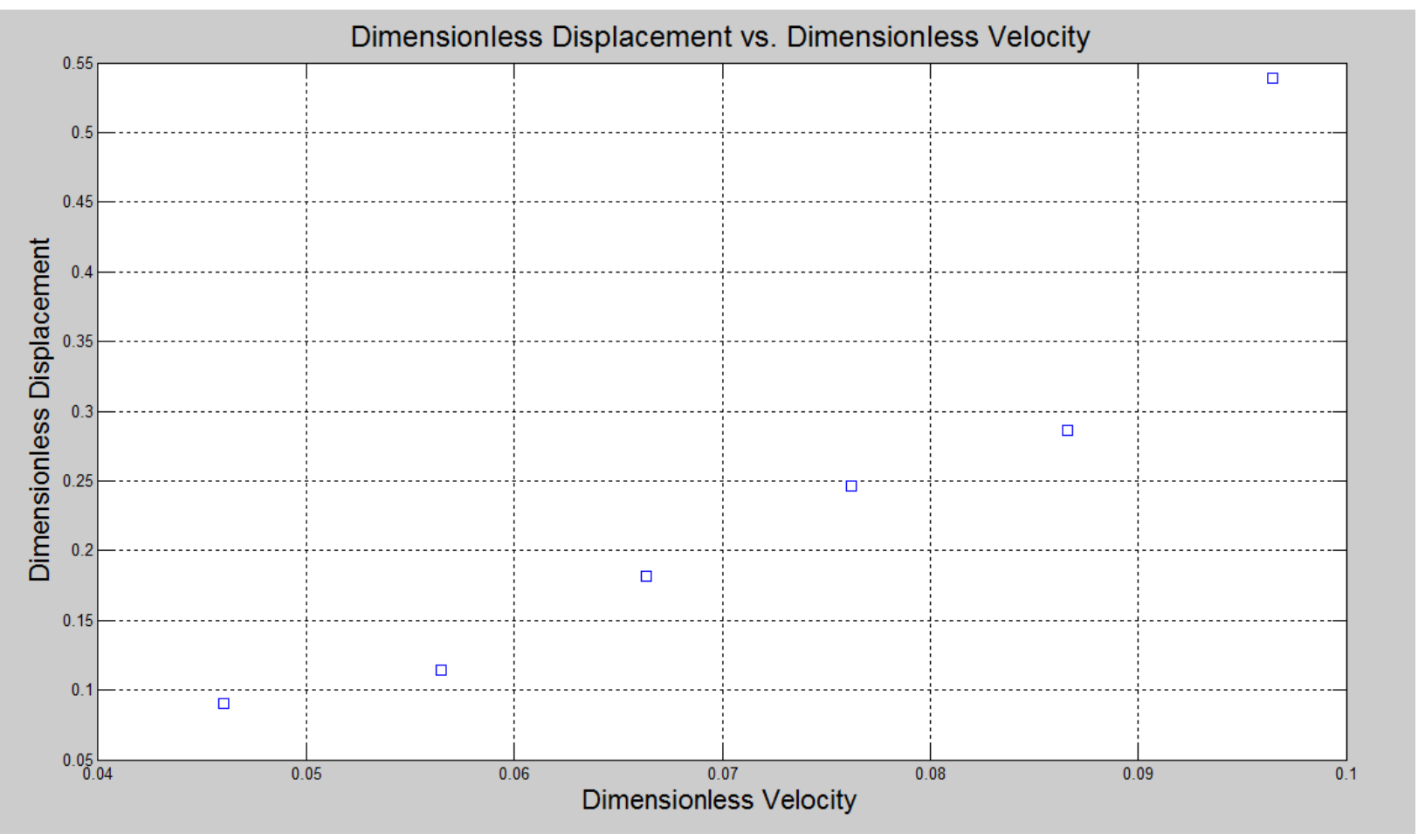

Figure 7.1: Dimensionless displacement vs. dimensionless velocity at tip sensor in vertical direction

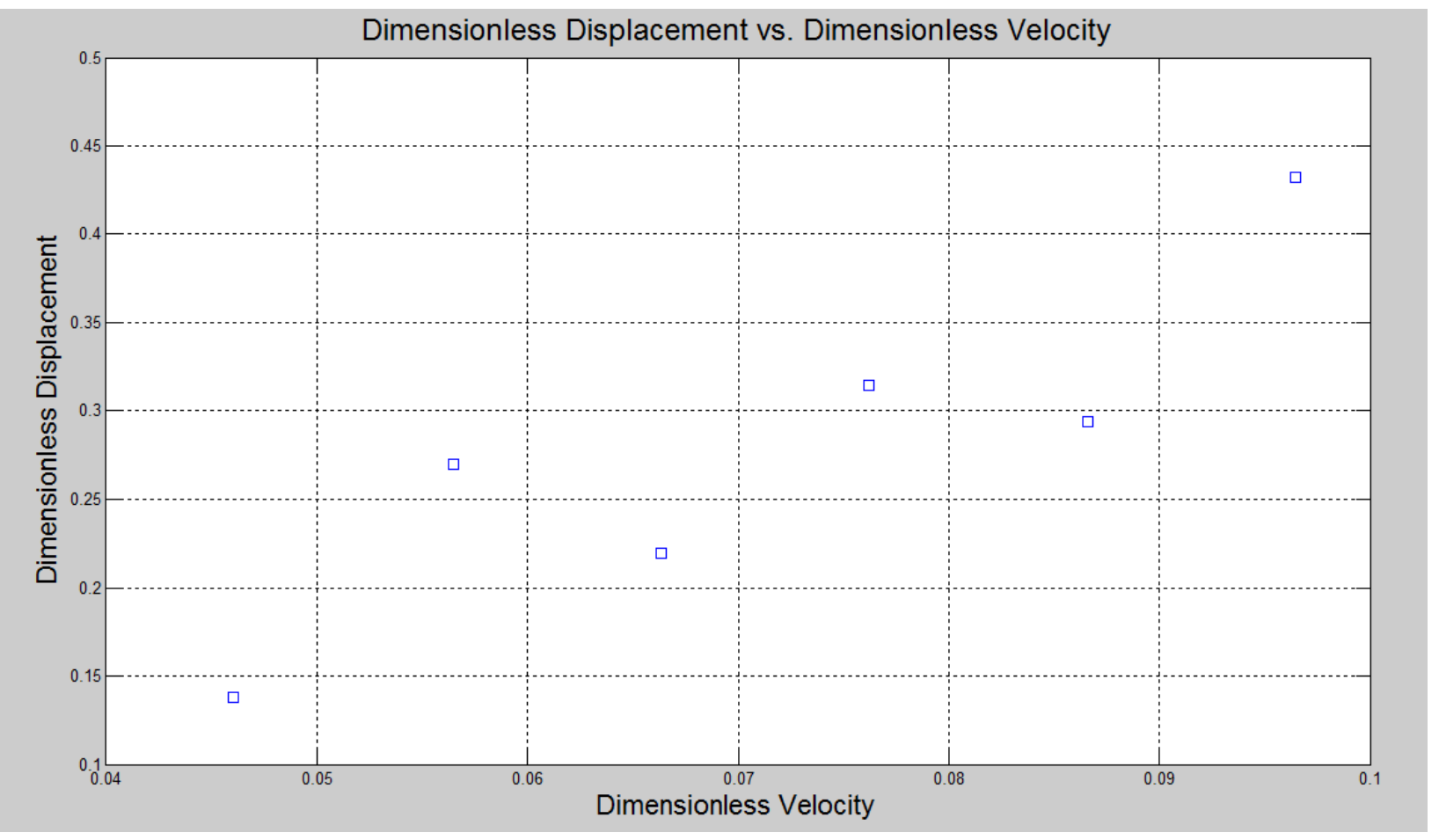

Figure 7.2: Dimensionless displacement vs. dimensionless velocity at tip sensor in horizontal direction 


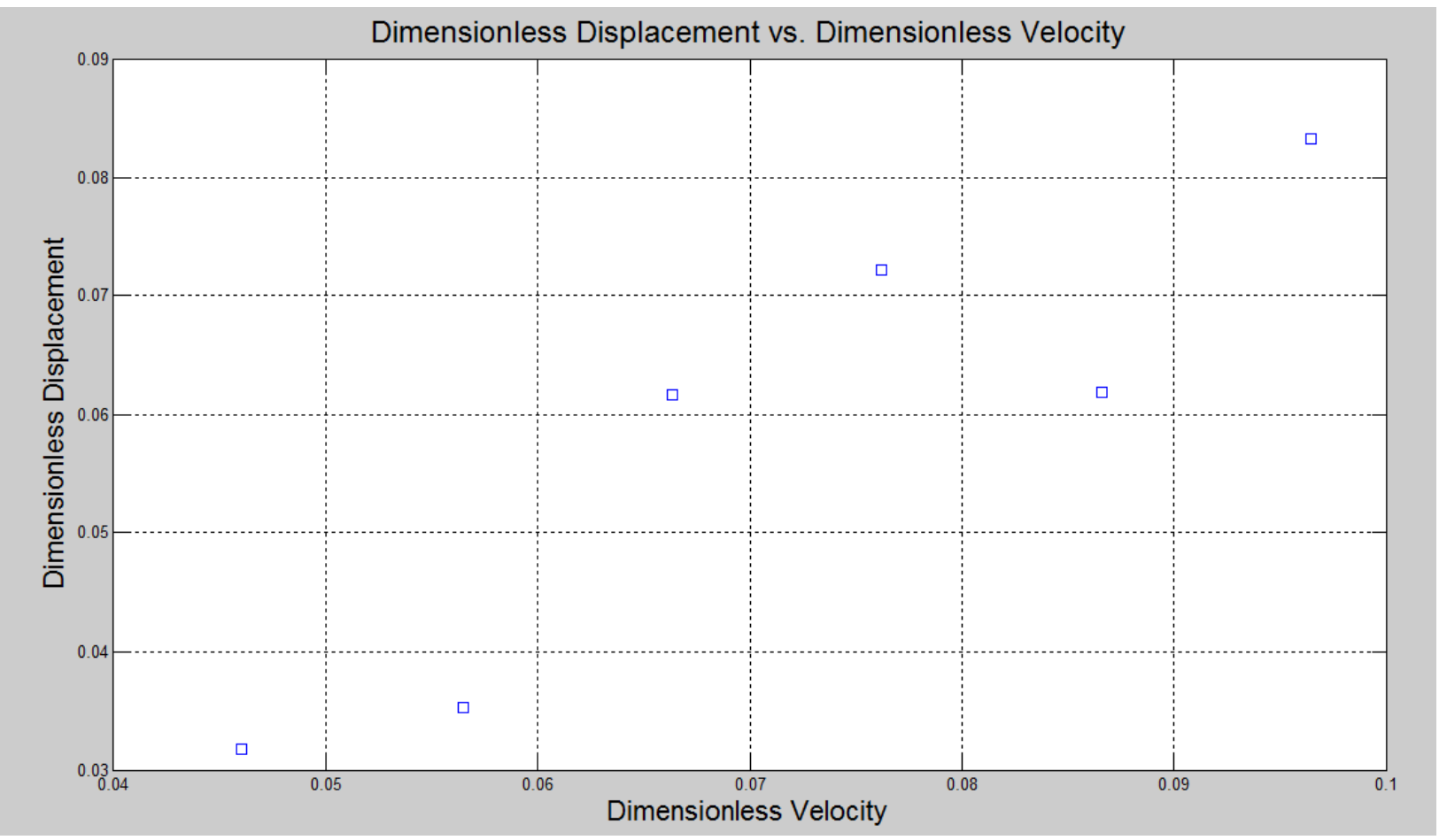

Figure 7.3: Dimensionless displacement vs. dimensionless velocity at base sensor in vertical direction

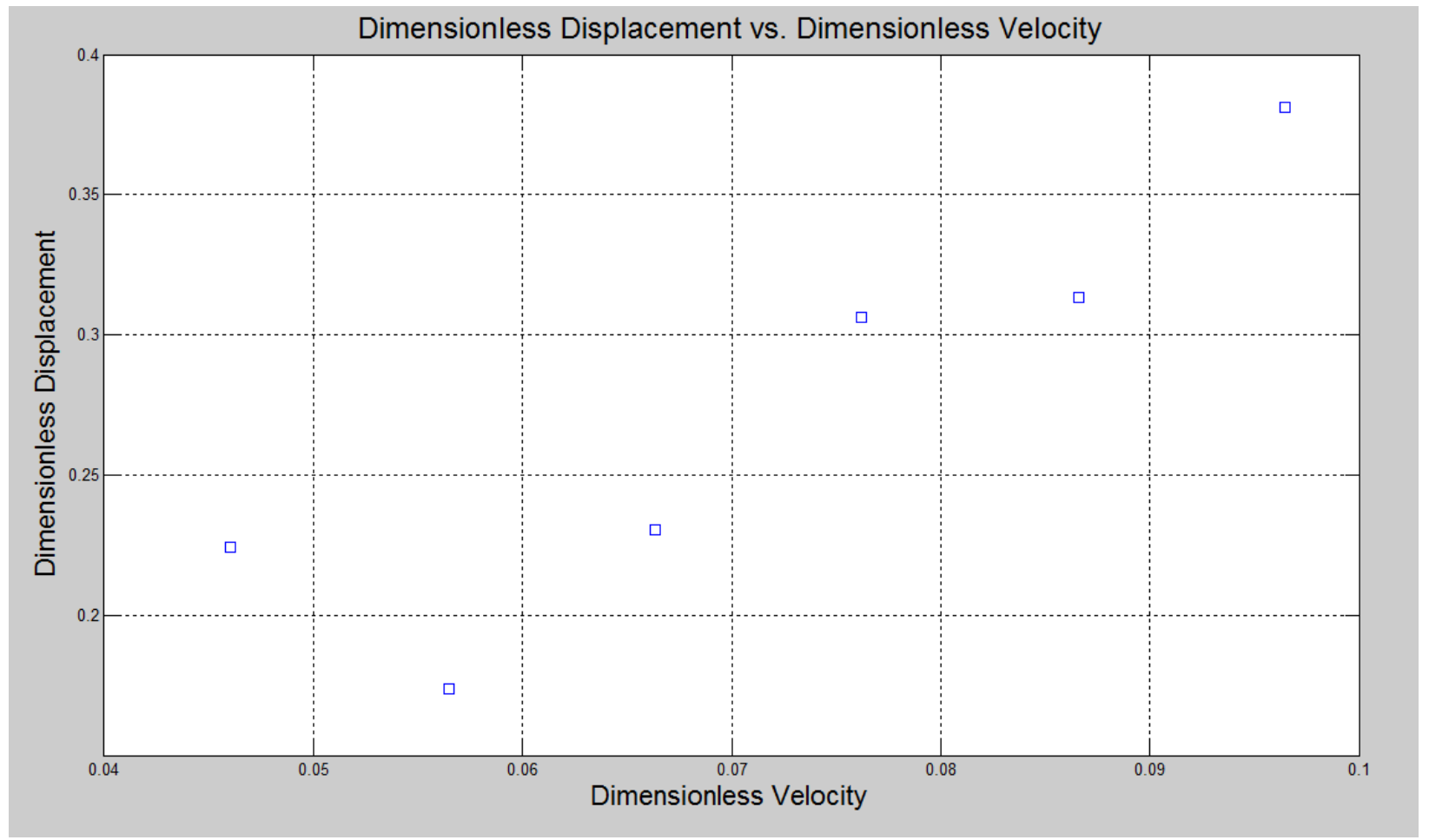

Figure 7.4: Dimensionless displacement vs. dimensionless velocity at base sensor in horizontal direction 
The formula used to calculate the dimensionless velocity was shown in the theory section but a sample calculation is shown below:

$$
\begin{gathered}
u=\sqrt{\frac{\rho A}{E I}} U l_{s} \\
I=\frac{\pi\left(d_{o}{ }^{4}-d_{i}{ }^{4}\right)}{64} \\
\rho=1000^{\mathrm{kg} / \mathrm{m}^{3}} \\
A=3.17 \times 10^{-5} \mathrm{~m}^{2} \\
E=119 \times 10^{9} \mathrm{~Pa} \\
d_{o}=6.35 \mathrm{~mm} \\
d_{i}=4.83 \mathrm{~mm} \\
I=5.32 \times 10^{-11} \mathrm{~m}^{4} \\
U=0.775 \mathrm{~m} \\
U=1.76^{\mathrm{m} / \mathrm{s}}
\end{gathered}
$$

Substituting all these values into the above equation gives the following value for the dimensionless velocity:

$$
u=0.0965
$$


As can be seen from the graph and the calculations, the maximum dimensionless flow velocity reached is approximately 0.0965 . This is well below the dimensionless velocity needed to achieve fluid-elastic instability, which is approximately 2.

Slender structures have a neutral point where the tension and compression forces acting on the rod are in balance. It is assumed that the tension/compression relationship is still in play on the rod used in this experiment. A theoretical analysis of that relationship is beyond the scope of this work. To determine the dimensionless velocity necessary to achieve instabilities the compression length must be calculated. This was calculated using the following formula [9]:

$$
L_{c}=\frac{D\left(\pi-2 C_{b}\right)}{2 C_{T}}
$$

Using typical values for the coefficients $C_{b}$ and $C_{T}$ yields a neutral point location that is approximately 100 times the diameter of the cylinder in question [9].

$$
L_{c}=100(0.00635)=0.635 \mathrm{~m}=63.5 \mathrm{~cm}
$$

Taking the ratio of the length to the compression length gives the effective length. If this ratio is greater than 1 then the neutral point exists on the rod in question [9]:

$$
l=\frac{L}{L_{c}}=\frac{1}{0.819}=1.22
$$


Therefore the neutral point on the rod used in this experiment exists and has been shown that its location has little effect on the measurements of the sensors, based on the placement of the sensors with respect to this neutral point.

The new dimensionless flow velocity accounting for the length of the rod is calculated using the following formula [9]:

$$
v=\frac{u}{l}
$$

Using the maximum dimensionless flow velocity gathered from the data and the length ratio calculated above the maximum value for small v:

$$
v=\frac{0.0965}{1.22}=0.0791
$$

The work of de Langre et al. shows that a rod needs a dimensionless velocity of between 1 and 4 to achieve fluid-elastic instability depending on the depending whether the rod is stable or unstable at high effective lengths. This means that the measurements from this experiment are far too low to achieve fluid elastic instability

Even taking into account the maximum fluid velocity that the experimental equipment is capable of, which is approximately $3.28 \mathrm{~m} / \mathrm{s}$, the calculation for the dimensionless velocity yields the following value for v:

$$
u=\sqrt{\frac{1000 * 3.15 \times 10^{-7}}{119 \times 10^{9} * 5.32 \times 10^{-11}}} * 0.775 * 3.28
$$




$$
\begin{gathered}
u=0.0707 * 3.28=0.232 \\
v=\frac{0.232}{1.22}=0.19
\end{gathered}
$$

Once again this number is not high enough to achieve either type of fluid-elastic instability: non-oscillating or oscillating. The hollow copper tubing used as the rod has material properties such that neither type of fluid-elastic instability can be generated by this experimental setup. This result is supported by Païdoussis, who notes that fluid-elastic instabilities using metallic rods require impractical fluid velocities

\subsection{Parametric Response}

To test whether the acoustic energy from the pump has any significant effect on the motion of the rod, an accelerometer was first placed on the outside of the pipe between the pump and the flow meter to measure the energy transmitted through the piping. Knowing that the pump contains 7 vanes as well as the RPM of the motor, it is possible to calculate the vane passing frequency using the formula below [7]:

$$
f_{\text {passing }}=\left(\frac{R P M}{60}\right) n_{\text {vanes }}=f_{\text {shaft }}\left(n_{\text {vanes }}\right)
$$

A relationship is known to exist between the shaft rotation frequency and the voltage

frequency displayed on the motor control unit, so an estimate of the shaft rotation frequency can be made for any voltage frequency. Using the relationship between the voltage frequency and the motor rotation frequency [15]: 


$$
f_{\text {voltage }}=\frac{P}{2} \frac{n}{60}=\frac{P}{2} f_{\text {shaft }}
$$

Based on the shaft frequency data from the tachometer measurements and the voltage frequency displayed on the motor control unit, it is shown that the number of poles in the motor is 4 . Using $30 \mathrm{~Hz}$ as the voltage frequency and using the corresponding shaft frequency measurement:

$$
\begin{aligned}
& P=\frac{2 f_{\text {voltage }}}{f_{\text {shaft }}} \\
& P=\frac{2(30)}{13.4} \cong 4
\end{aligned}
$$

Now the relationship between the voltage frequency and the shaft frequency can be written:

$$
f_{\text {voltage }}=\frac{4}{2} f_{\text {shaft }}=2 f_{\text {shaft }}
$$

Substituting the relationship between the voltage and the shaft frequencies, the following equation is obtained:

$$
f_{\text {vane passing }} \sim\left(\frac{f_{\text {voltage }}}{2}\right) n_{\text {vanes }}
$$


Using this vane passing frequency formula with an accelerometer placed on the outside of the piping between the pump and the flow meter, a measurement of the energy present at the vane passing frequency of the pump in the pipe system can be made. Figure 7.5 below shows the acceleration power spectrum density taken under flow conditions with a voltage frequency of $40 \mathrm{~Hz}$ and a calculated vane passing frequency of approximately $140 \mathrm{~Hz}$ :

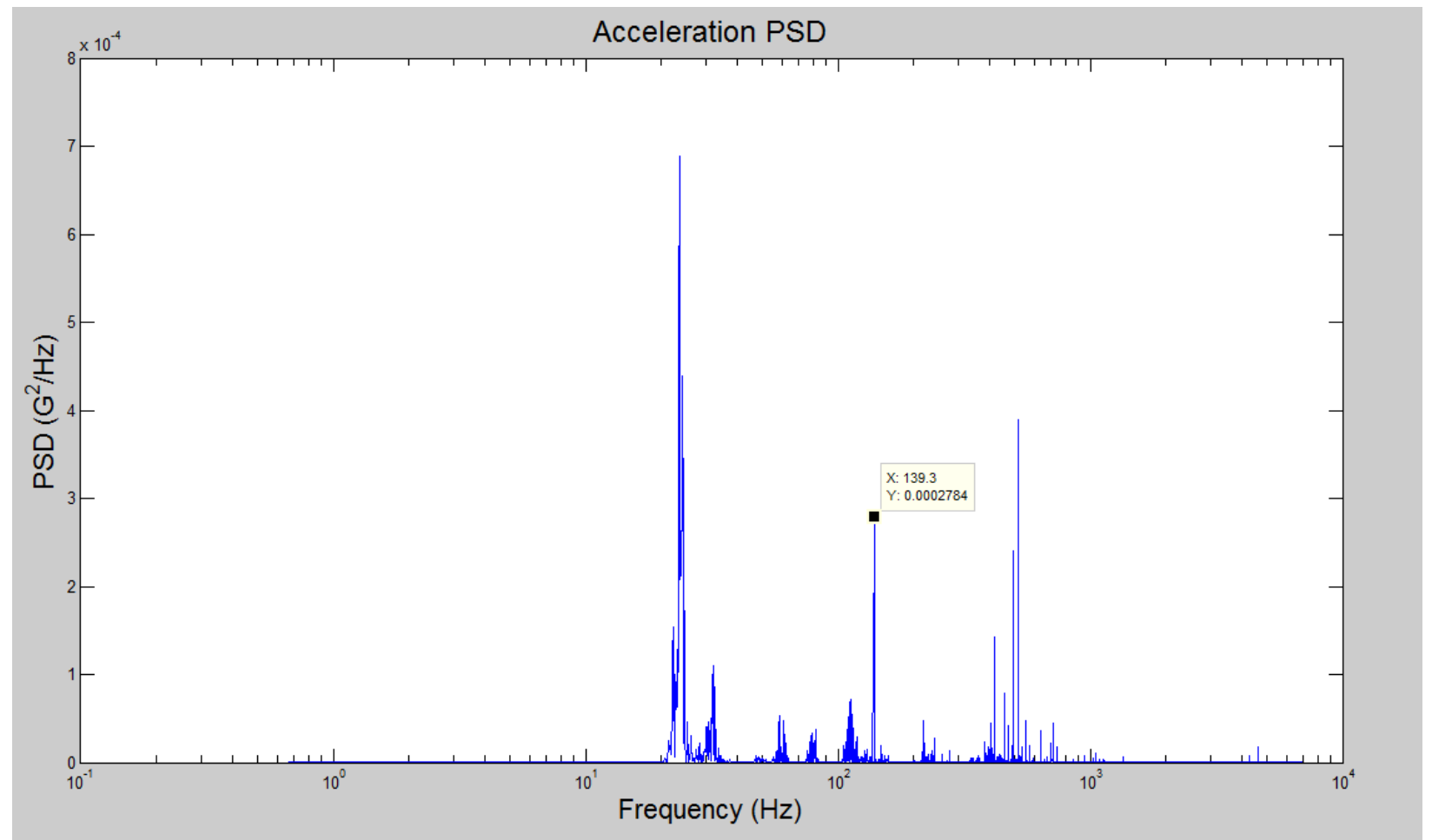

Figure 7.5: Acceleration power spectrum density with vane passing frequency marked

As can be seen the peak at $139.3 \mathrm{~Hz}$ shows the acoustic energy from the pump is far from insignificant in compared with the other frequencies measured. By comparison, the acceleration power spectrum density from the rod under operating conditions shown in figure 7.6 shows that the vane passing frequency contributes very little energy to the rod. The vane passing frequency in the case shown below is $101.64 \mathrm{~Hz}$ and was obtained from the tachometer data. 


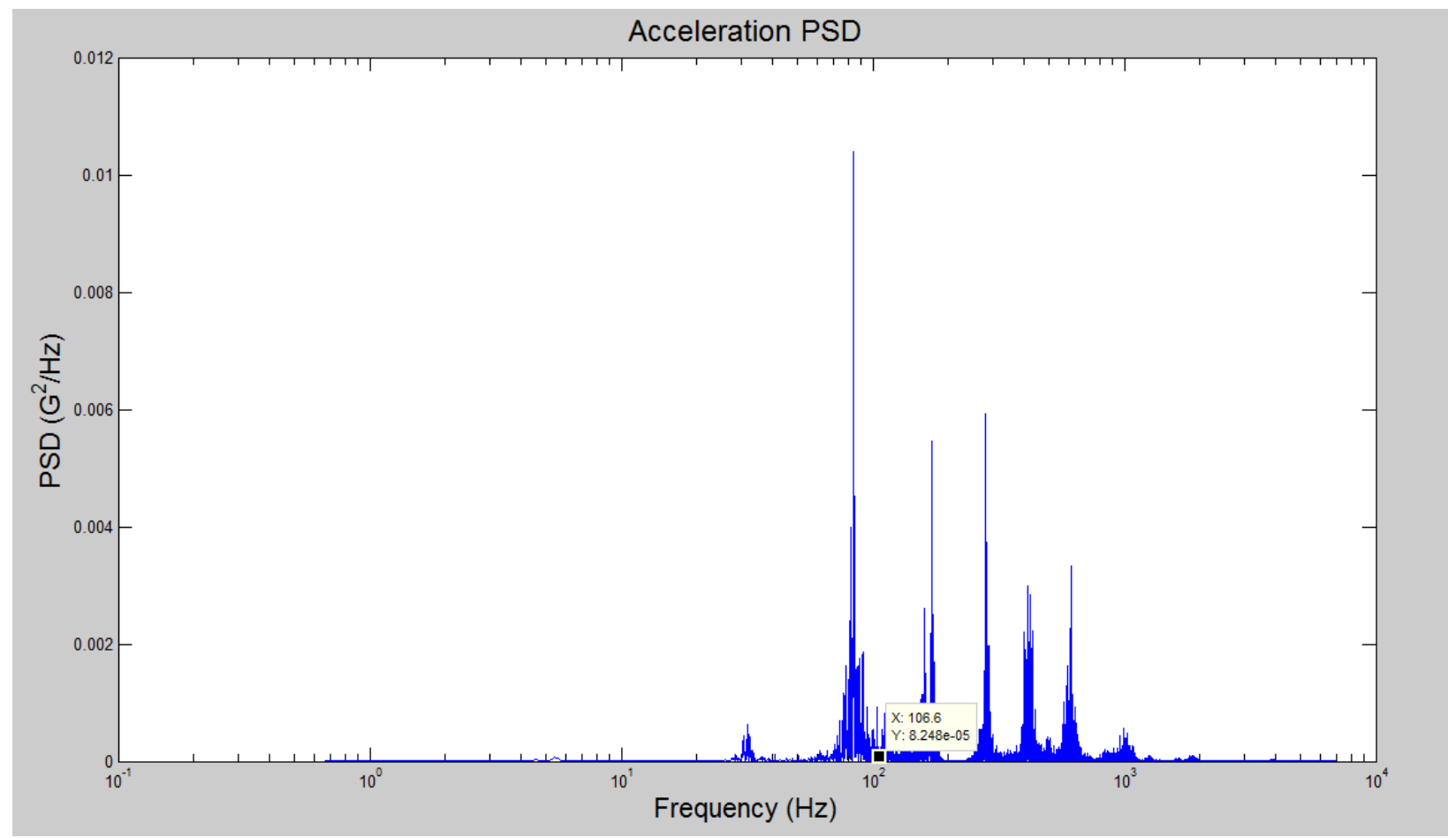

Figure 7.6: Acceleration power spectrum density under operation conditions with the acoustic frequency marked

As can be seen, from comparing these two figures, the acoustic energy measured in the rod is several orders of magnitude smaller than the other frequencies measured by the accelerometers on the rod. The amplitude of the vane passing frequency is 1 order of magnitude smaller than that measured on the outside of the pipe. From these measurements the observation is that the acoustic energy generated by the passing of the vanes of the pump past the pump outlet contributes very little energy to the rod and thus plays a negligible role in the observed motion. The composite displacement power spectrum density also supports this analysis as no peak is seen in or around the range of the vane passing frequencies of between 44.9 and $93.8 \mathrm{~Hz}$. 


\subsection{Non-Resonant Buffeting Response}

Eliminating two of the three sources of flow induced vibrations leaves non-resonant buffeting response as the likely type of response seen in the beam vibrations. Buffeting response occurs at dimensionless fluid velocities below 2 and the amplitude of the vibration is typically 2 or 3 orders of magnitude less than the diameter of the rod being examined. However the measured root mean square values of the vibrations in the experiment are less than 1 order of magnitude smaller than the diameter of the rod. Even though the vibration amplitude is large compared to the diameter and may appear to be unstable, the first mode continues to be the dominant bending frequency as can be seen in the displacement power spectrum densities. This shows that the fluid velocity necessary for non-oscillating fluid-elastic instability has not been reached yet, since the second mode would be the dominant mode if that were the case [1].

However this does not explain the increase in the amplitude of the vibrations compared to the work previously done by other authors. Some investigations have been done into a blunt cylinder in axial flow to investigate shear layer separation and reattachment. Their experiments showed that the shear layer separates from the cylinder at the blunt tip and reattaches itself at a point along the cylinders length. This separated shear layer creates a flow separated bubble from the tip to approximately 1.5 times the diameter [10]:

This bubble is a very complex unsteady flow system which interacts with the surface of the cylinder [10]. The cylinder in the experiment done by Higuchi et al. was fixed but the rod in the experiment work done here was free to move and, at the maximum flow rate of the 
experiment, achieved a similar Reynolds number to the work of Higuchi et al. The calculation is shown below [16]:

$$
R e=\frac{\rho U d_{\text {rod }}}{\mu}
$$

The values for the fluid properties are those of water at 25 degrees Celsius. The rod in this experiment was free to move at the tip and would be subject to this trapped area of unsteady flow. The height of this unsteady velocity profile extends up to $80 \%$ of the diameter off the surface of the cylinder. This is a similar range of amplitude to diameter ratios that were observed in the data gathered in this experiment and at a similar Reynolds number to that seen in Higuchi et al's work: 10,000 in the experiment done by Higuchi et al compared to 12,165 in this experiment.

From comparisons between the displacement power spectrum densities of the data gathered from this experiment and those of Païdoussis, the observation can be made that the rod in the current experiment is experiencing flow velocities below what is necessary to achieve either non-oscillatory or oscillatory fluid-elastic instabilities. Also the displacement power spectrum densities show no significant peaks at or around the vane passing frequencies associated with each mass flow rate indicating that little acoustic energy is present in the motion of the rod. 


\section{Chapter 8 Conclusion}

This experiment was designed to identify the response of flow induced vibrations in a cantilevered rod with the free boundary condition upstream in axial flow. Using the data gathered from accelerometers and the associated power spectrum densities it was possible to determine the vibration response from the known types of fluid structure interactions. Fluidelastic instability can be ruled out, as the velocities required to achieve such phenomena are far in excess of what could be generated by the system used in this experiment. Also the first mode of bending vibration remained the dominant mode through the range of flow velocities again indicating that fluid elastic instability had not occurred. Parametric response can also be ruled out, as the acoustic energy generated by the pump is prominently seen in the power spectrum density taken on the outside of the piping but has a negligible contribution to the energy in the rod. This can be seen not only in the acceleration power spectrum densities but also in the displacement power spectrum densities because the frequency associated with the vane passing frequency has no visible peak. Eliminating these two responses leaves only nonresonant buffeting response as the type of phenomena observed. This is in line with previous work because the first mode bending remains the dominant bending frequency measured.

Some differences have been noted between this work and the experiments that have been done by other researchers. Even with the very small non-dimensional fluid velocity large amplitude to rod diameter ratios were observed, far larger than has been seen in previous experiments. Comparing the data appears to suggest that a cantilevered rod that is clamped upstream is more stable than a rod clamped downstream, even if the materials used in the previous experiments were far less stiff than the material used in this experiment. 
In spite of the fact that the fluid flow velocities were insufficient to produce divergence or fluttering, the amplitude of the vibration was quite large in comparison to the diameter of the rod. Comparing with previous experiments done by Paidoussis, the results obtained are 1 order of magnitude larger than has been previously obtained. Investigations into blunt cylinders in axial flow revealed that a trapped shear layer bubble remains at the very tip of the rod. The unsteady velocity profile extends up to $80 \%$ the diameter of the cylinder above the surface of the cylinder at a Reynolds number of 10,000. The experiment performed achieved an amplitude-diameter ratio of around 0.55 with a Reynolds number of 12,165.

This thesis shows that, at least in principle, the dynamics of the rod in the experiment can be described by the previous theories that have been developed. The differences between the observed amplitude of vibration seen in this experiment and the amplitude of vibration predicted by previous work indicates that there is more to this phenomena to be understood through future experiments and theoretical analysis. 


\section{Appendices}

\section{Appendix 1: MATLAB program used to provide composite plots}

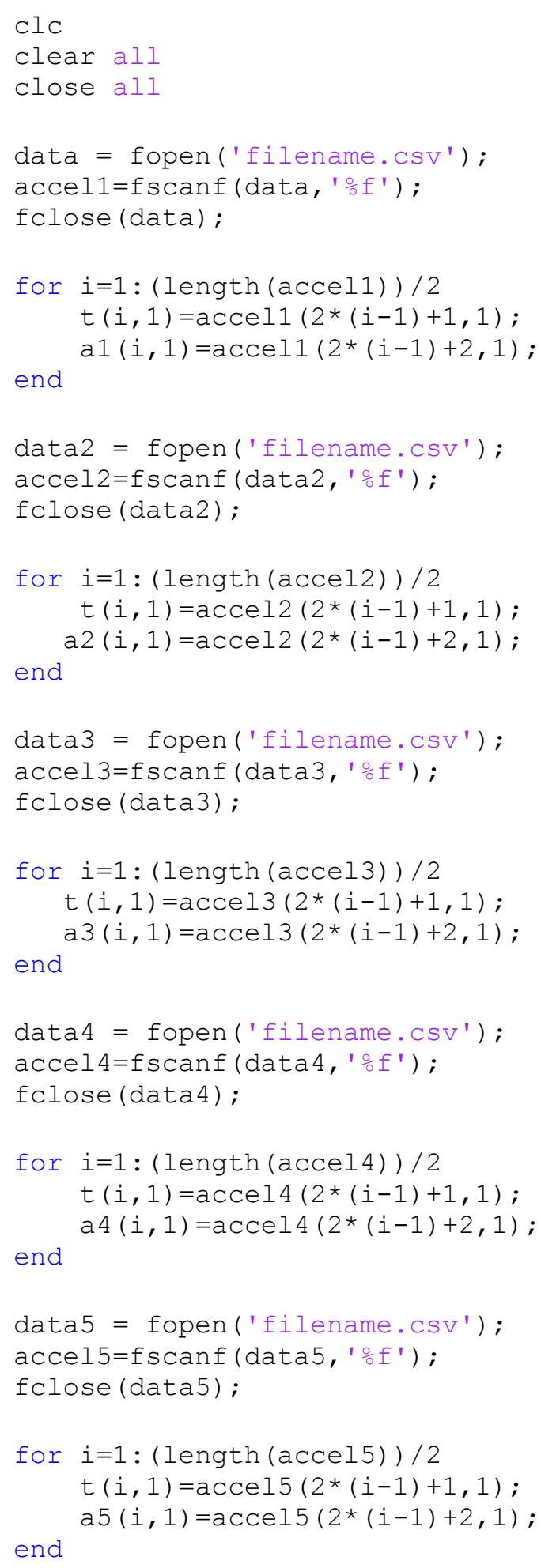




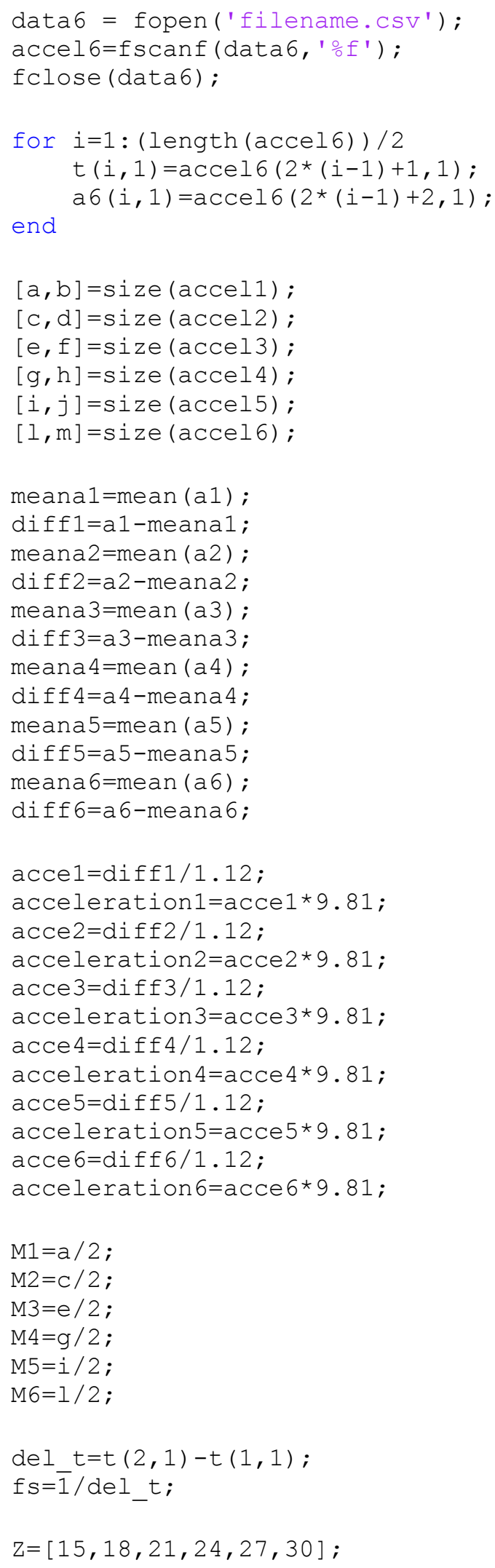


$\mathrm{fl}=\mathrm{fs} / 2 * 1$ inspace $(0,1, \mathrm{a} / 2)$ ';

f2 $=f \mathrm{~s} / 2 *$ linspace $(0,1, \mathrm{c} / 2)$ ';

f3 $=\mathrm{fs} / 2 *$ linspace $(0,1, \mathrm{e} / 2)$ ' ;

$\mathrm{f4}=\mathrm{fs} / 2 *$ linspace $(0,1, \mathrm{~g} / 2)$ ';

$\mathrm{f5}=\mathrm{fs} / 2 *$ linspace $(0,1, \mathrm{i} / 2)$ ' ;

$\mathrm{f} 6=\mathrm{fs} / 2 *$ linspace $(0,1, i / 2)$ ' ;

$\mathrm{Bw} 1=\mathrm{fs} / \mathrm{a}$;

$\mathrm{Bw} 2=\mathrm{fs} / \mathrm{C}$;

$\mathrm{Bw} 3=\mathrm{fs} / \mathrm{e}$;

$\mathrm{Bw} 4=\mathrm{fs} / \mathrm{g}$;

$\mathrm{Bw} 5=\mathrm{fs} / \mathrm{i}$;

$\mathrm{Bw} 6=\mathrm{fs} / \mathrm{I}$;

Resolution $1=\mathrm{fs} / \mathrm{a}$;

Resolution $2=\mathrm{fs} / \mathrm{C}$;

Resolution $3=f s / e$;

Resolution $4=\mathrm{fs} / \mathrm{g}$;

Resolution $5=f s / i$;

Resolution $6=f s / 1$;

nfcl=2000/Resolution 1 ;

nfc2=2000/Resolution2;

nfc3 $=2000 /$ Resolution3;

nfc4=2000/Resolution4;

nfc $5=2000 /$ Resolution 5 ;

nfc $6=2000 /$ Resolution 6 ;

figure

subplot $(6,1,1)$

$\operatorname{plot}(t, \operatorname{acce} 6)$

title('Mass Flow Rate $=0.843 \mathrm{~kg} / \mathrm{s}^{\prime}$, 'FontSize', 14)

$\operatorname{axis}\left(\left[\begin{array}{llll}0 & 6.7 & -2 & 2\end{array}\right]\right)$

subplot $(6,1,2)$

plot $(t, \operatorname{acce} 5)$

title ('Mass Flow Rate $=1.34 \mathrm{~kg} / \mathrm{s}$ ', 'FontSize',14)

axis ([ $\left.\left[\begin{array}{llll}0 & 6.7 & -2 & 2\end{array}\right]\right)$

subplot $(6,1,3)$

plot $(t, \operatorname{acce} 4)$

title('Mass Flow Rate $=1.85 \mathrm{~kg} / \mathrm{s}$ ', 'FontSize', 14)

$\operatorname{axis}\left(\left[\begin{array}{llll}0 & 6.7 & -2 & 2\end{array}\right]\right)$

subplot $(6,1,4)$

$\operatorname{plot}(t, \operatorname{acce} 3)$

title ('Mass Flow Rate $=2.45 \mathrm{~kg} / \mathrm{s}$ ', 'FontSize',14)

$\operatorname{axis}\left(\left[\begin{array}{llll}0 & 6.7 & -2 & 2\end{array}\right]\right)$

subplot $(6,1,5)$

plot $(t, \operatorname{acce} 2)$

title('Mass Flow Rate $=3.19 \mathrm{~kg} / \mathrm{s}$ ', 'FontSize',14) 


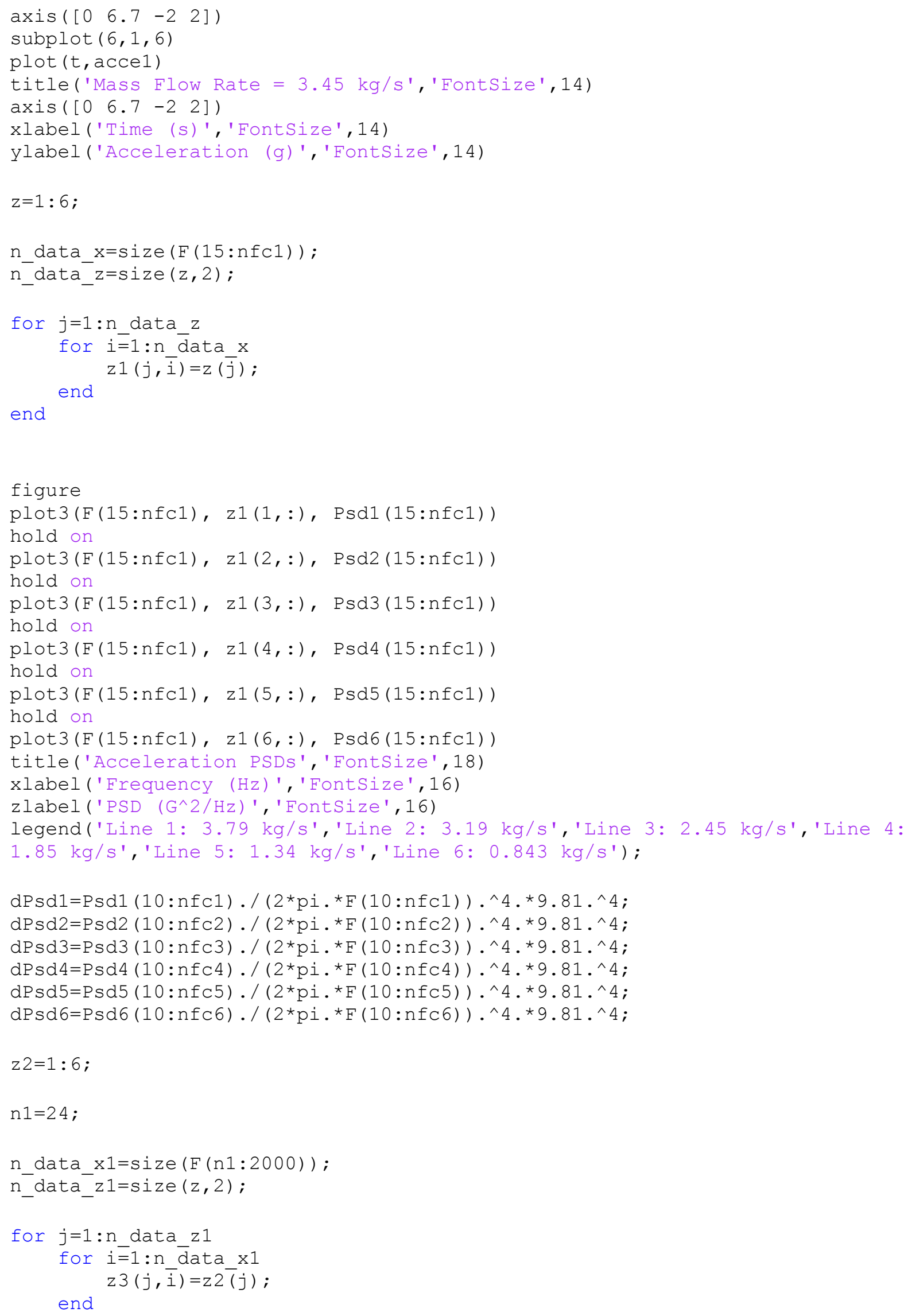




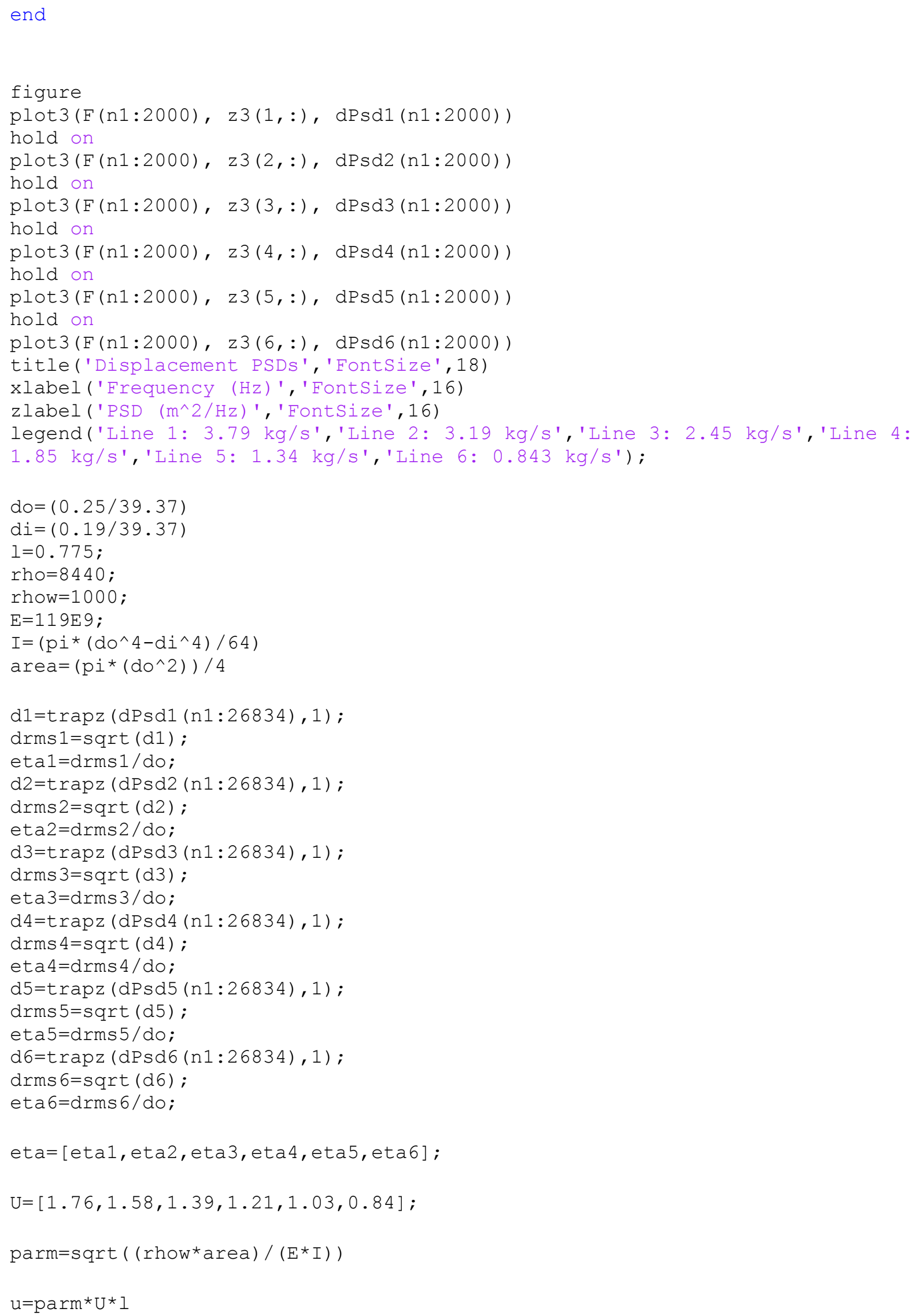


figure

plot (u, eta, 's')

grid on

title('Dimensionless Displacement vs. Dimensionless Velocity','Fontsize', 18)

xlabel ('Dimensionless Velocity', 'FontSize', 16)

ylabel ('Dimensionless Displacement', 'FontSize', 16) 


\section{Appendix 2: MATALB program for determining the mode shapes}

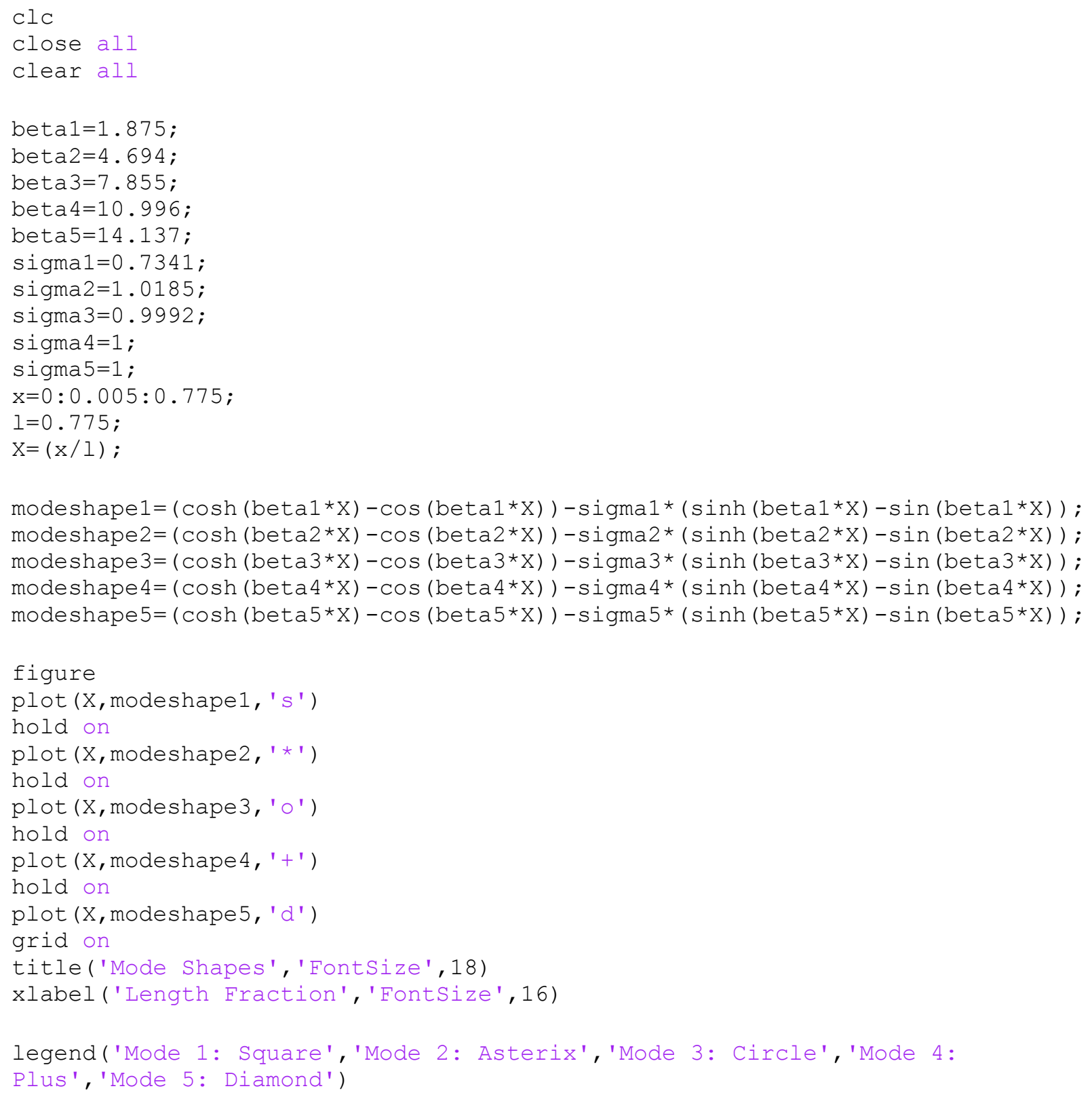




\section{Appendix 3: Program used to generate acceleration vs. time graphs}

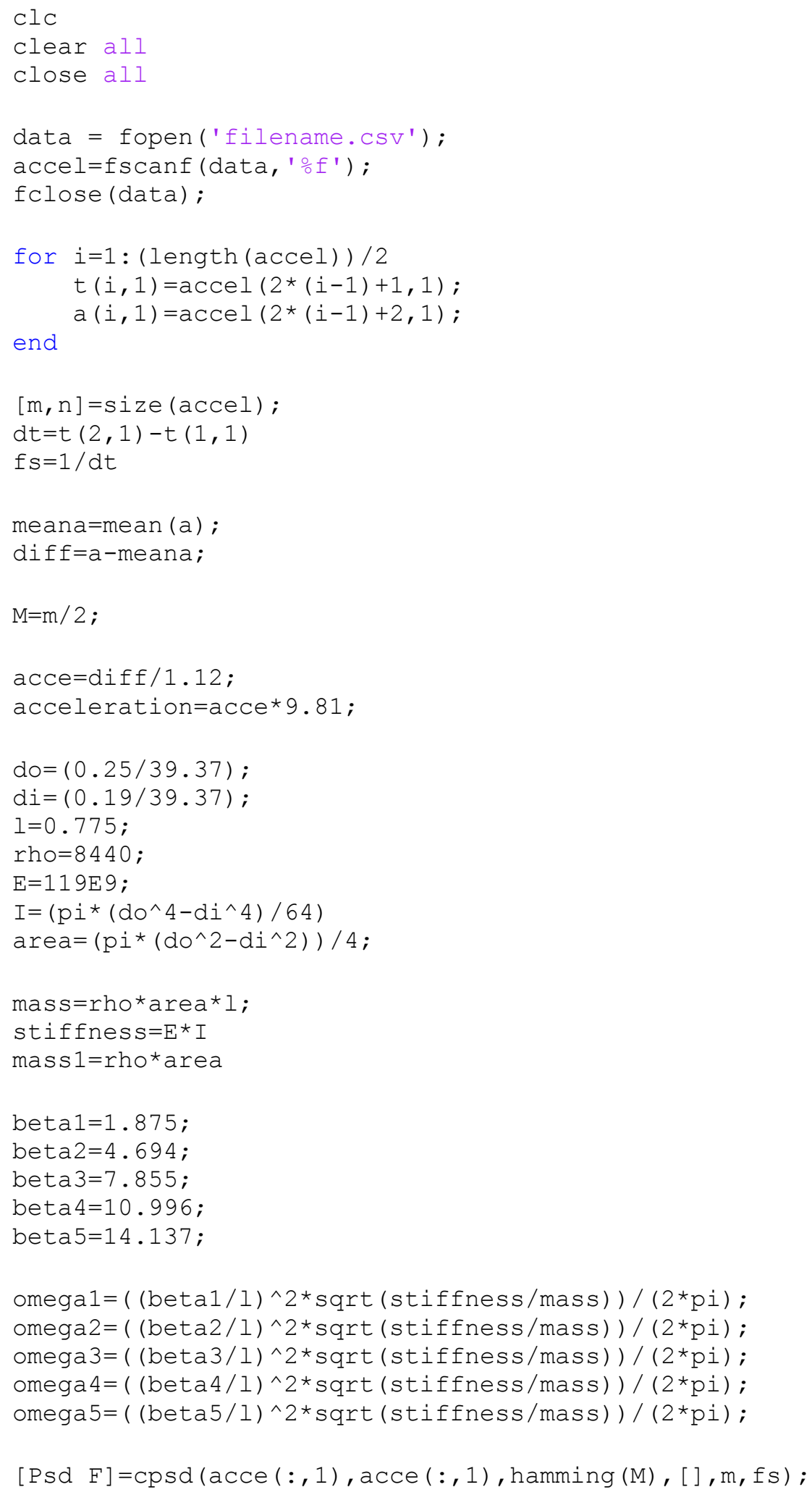




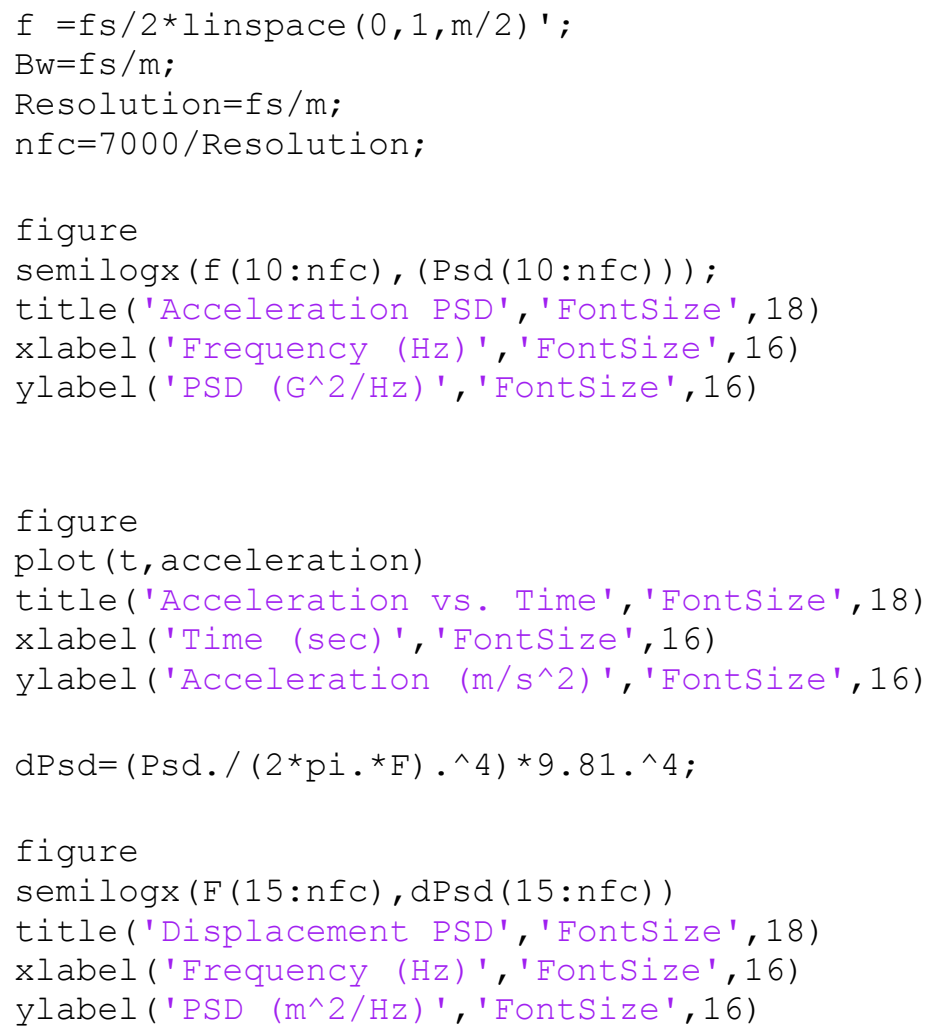


Appendix 4: Positions of sensors during gravity calibration

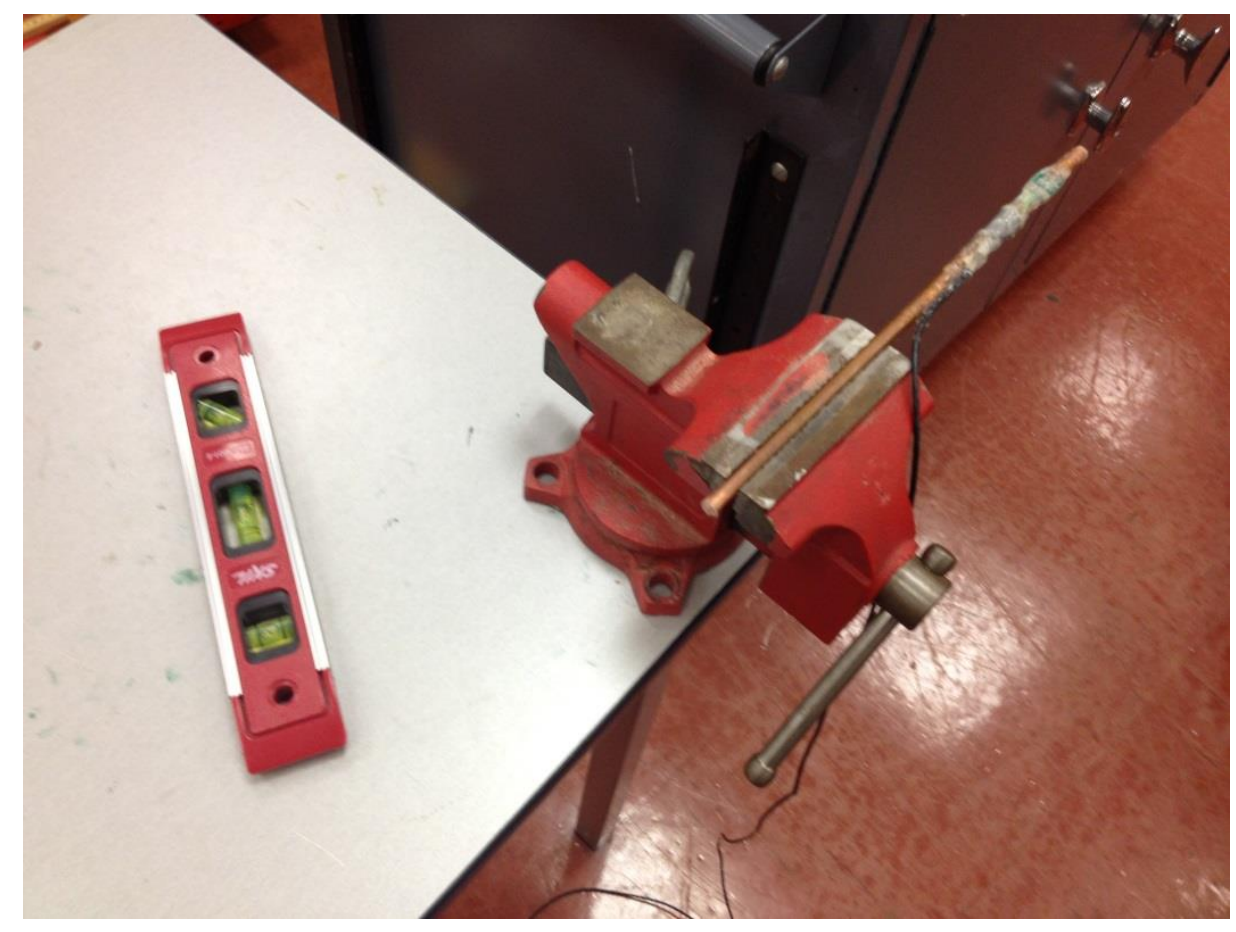

First or neutral position

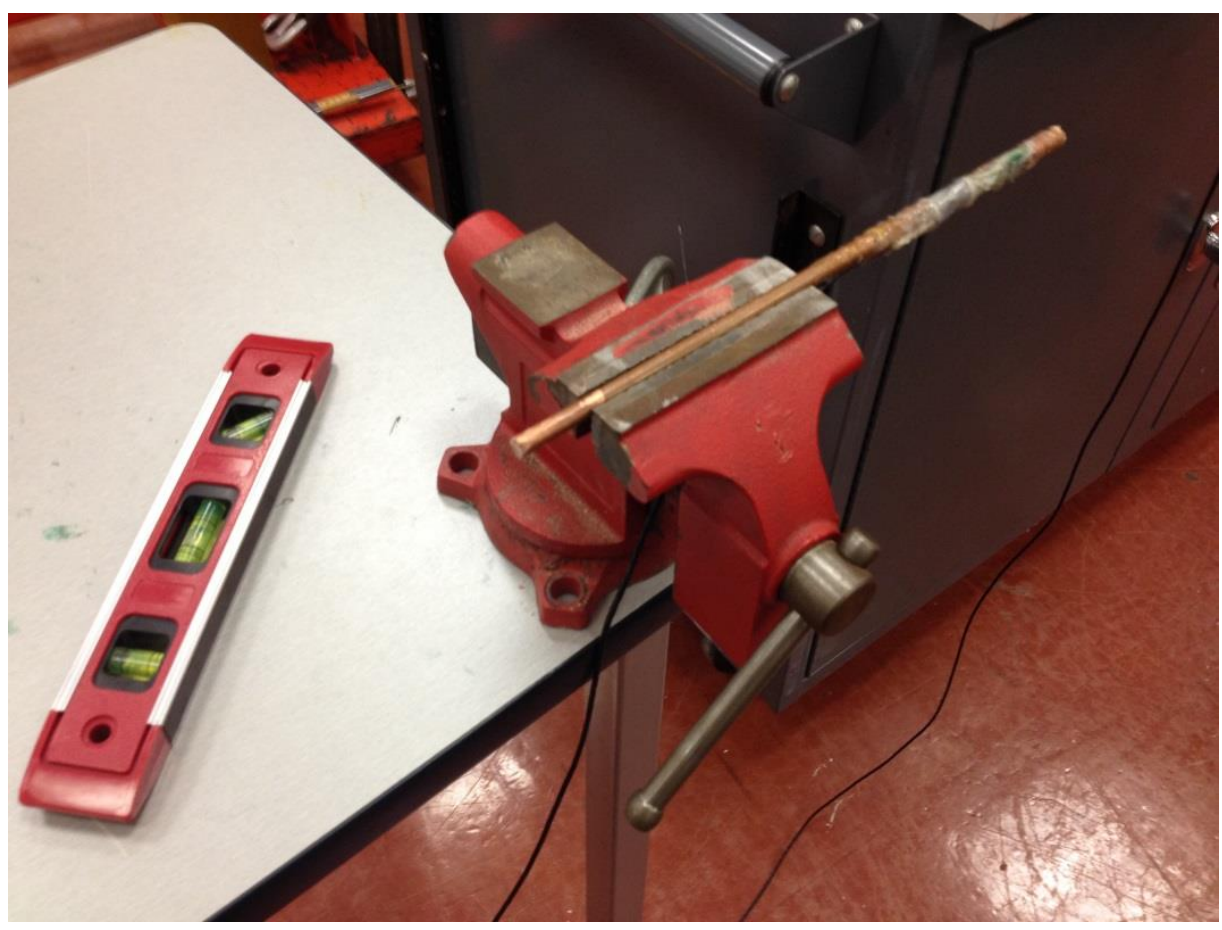

Second position with y axis facing down 


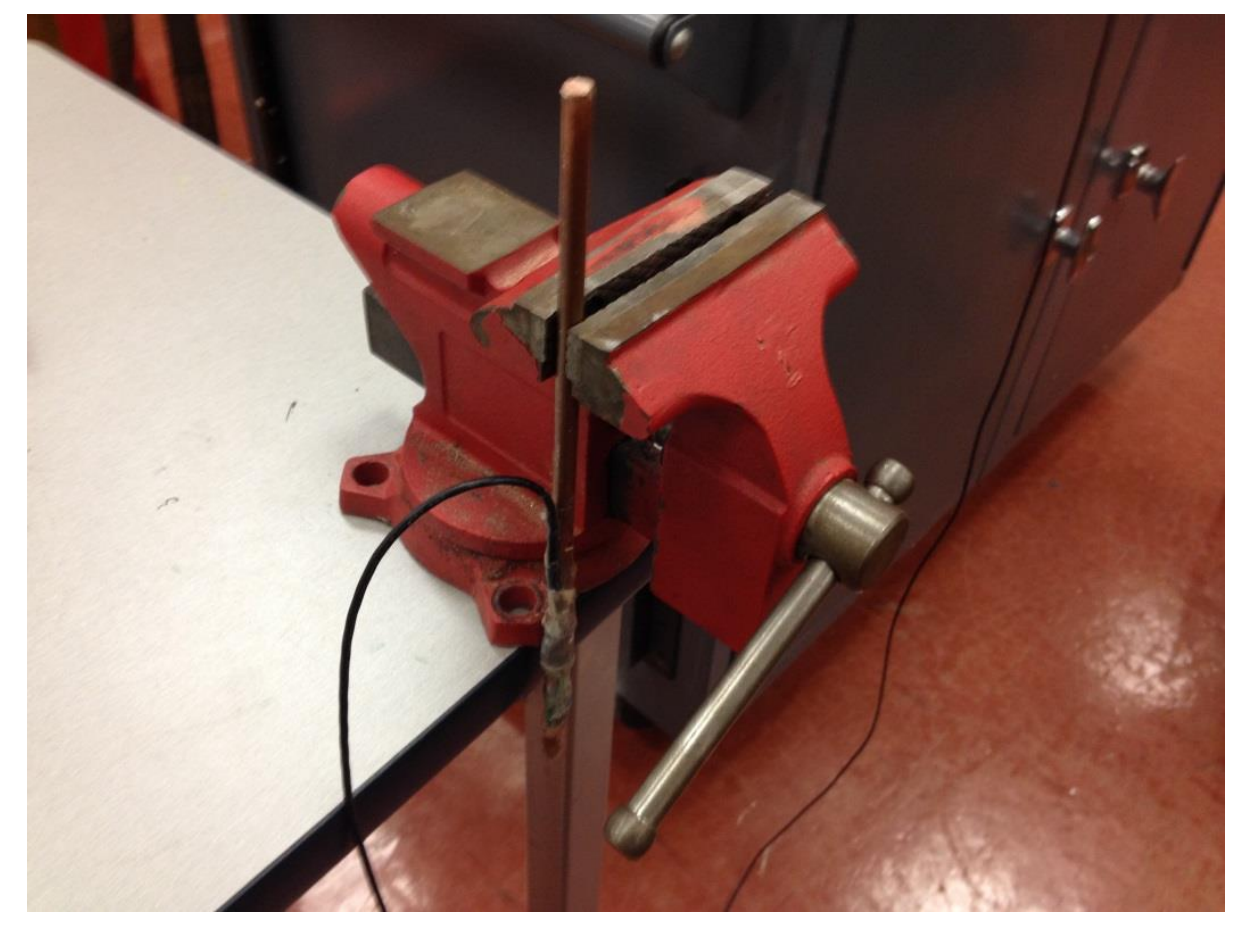

Position 3 with $\mathrm{x}$ axis facing down 


\section{Appendix 5: Sample of data from sensor calibration}

The three numbers next to each column are, from top to bottom:

1. The average measured voltage in volts

2. The standard deviation in volts

3. The standard deviation in millivolts.

$\begin{array}{rr}\text { HorizontalX } & \\ 2.6992188 & 2.692143 \\ 2.6992188 & 0.005818 \\ 2.6933594 & 5.818311 \\ 2.6992188 & \\ 2.6972656 & \\ 2.6992188 \\ 2.6953125 \\ 2.6992188 \\ 2.6953125 \\ 2.6933594 \\ 2.6933594 \\ 2.6914063 \\ 2.6953125 \\ 2.6816406 \\ 2.6875 \\ 2.7226563 \\ 2.6835938 \\ 2.7089844 \\ 2.6972656 \\ 2.6894531 \\ 2.7011719 \\ 2.6972656 \\ 2.7011719 \\ 2.7050781 \\ 2.6914063 \\ 2.7109375 \\ 2.6894531 \\ 2.6914063 \\ 2.6972656 \\ 2.6953125 \\ 2.6875 \\ 2.6914063 \\ 2.6992188 \\ 2.6933594 \\ \\ \end{array}$

XVerticalX

$1.5751953 \quad 1.574395$

$1.5751953 \quad 0.00438$

$\begin{array}{ll}1.5664063 & 1.124824\end{array}$

1.5722656

1.5742188

1.5634766

1.5693359

1.5664063

1.5742188

1.5742188

1.5761719

1.5732422

1.5751953

1.5693359

1.5800781

1.5605469

1.5712891

1.5693359

1.5664063

1.5664063

1.5712891

1.5644531

1.5683594

1.5761719

1.5634766

1.578125

1.5664063

1.5761719

1.5625

1.5751953

1.5712891

1.578125

1.5634766

1.5683594
YVerticalY

3.769531

$3.78125 \quad 0.006738$

$3.777344-3.78051$

3.769531

3.78125

3.785156

3.773438

3.765625

3.785156

3.773438

3.78125

3.773438

3.78125

3.761719

3.769531

3.777344

3.753906

3.777344

3.773438

3.777344

3.777344

3.773438

3.773438

3.773438

3.777344

3.773438

3.777344

3.777344

3.777344

3.761719

3.78125

3.78125

3.777344

3.773438 


\begin{tabular}{|c|c|c|}
\hline 2.703125 & 1.5712891 & 3.773438 \\
\hline 2.6894531 & 1.5761719 & 3.785156 \\
\hline 2.6953125 & 1.5732422 & 3.769531 \\
\hline 2.6875 & 1.5654297 & 3.773438 \\
\hline 2.6914063 & 1.5722656 & 3.785156 \\
\hline 2.6914063 & 1.5654297 & 3.792969 \\
\hline 2.703125 & 1.5615234 & 3.777344 \\
\hline 2.6914063 & 1.5634766 & 3.773438 \\
\hline 2.6855469 & 1.5644531 & 3.777344 \\
\hline 2.6972656 & 1.5712891 & 3.777344 \\
\hline 2.7050781 & 1.5712891 & 3.765625 \\
\hline 2.6796875 & 1.5625 & 3.765625 \\
\hline 2.6992188 & 1.5693359 & 3.773438 \\
\hline 2.6894531 & 1.5703125 & 3.773438 \\
\hline 2.6953125 & 1.5722656 & 3.773438 \\
\hline 2.6835938 & 1.5771484 & 3.773438 \\
\hline 2.6914063 & 1.5693359 & 3.765625 \\
\hline 2.6914063 & 1.5683594 & 3.773438 \\
\hline 2.6953125 & 1.5683594 & 3.773438 \\
\hline 2.7011719 & 1.5693359 & 3.773438 \\
\hline 2.6875 & 1.5693359 & 3.769531 \\
\hline 2.6992188 & 1.5712891 & 3.773438 \\
\hline 2.6933594 & 1.5800781 & 3.773438 \\
\hline 2.7050781 & 1.5722656 & 3.78125 \\
\hline 2.6992188 & 1.5634766 & 3.769531 \\
\hline 2.6992188 & 1.5693359 & 3.773438 \\
\hline 2.6894531 & 1.5761719 & 3.773438 \\
\hline 2.6953125 & 1.5654297 & 3.765625 \\
\hline 2.6972656 & 1.5771484 & 3.765625 \\
\hline 2.6972656 & 1.5683594 & 3.765625 \\
\hline 2.6914063 & 1.5654297 & 3.773438 \\
\hline 2.6855469 & 1.5742188 & 3.773438 \\
\hline 2.703125 & 1.5742188 & 3.777344 \\
\hline 2.6972656 & 1.5732422 & 3.769531 \\
\hline 2.7128906 & 1.5693359 & 3.769531 \\
\hline 2.7011719 & 1.5664063 & 3.777344 \\
\hline 2.6894531 & 1.5664063 & 3.777344 \\
\hline 2.6972656 & 1.5693359 & 3.773438 \\
\hline 2.6933594 & 1.5742188 & 3.769531 \\
\hline 2.6875 & 1.5664063 & 3.773438 \\
\hline 2.6953125 & 1.5732422 & 3.773438 \\
\hline 2.6933594 & 1.5654297 & 3.78125 \\
\hline 2.703125 & 1.5654297 & 3.769531 \\
\hline
\end{tabular}




\begin{tabular}{|c|c|c|}
\hline 2.6972656 & 1.5634766 & 3.769531 \\
\hline 2.6972656 & 1.5664063 & 3.777344 \\
\hline 2.6875 & 1.5693359 & 3.761719 \\
\hline 2.6953125 & 1.5683594 & 3.773438 \\
\hline 2.6933594 & 1.5751953 & 3.773438 \\
\hline 2.6953125 & 1.5742188 & 3.773438 \\
\hline 2.6855469 & 1.5712891 & 3.785156 \\
\hline 2.6992188 & 1.5644531 & 3.789063 \\
\hline 2.6933594 & 1.5634766 & 3.777344 \\
\hline 2.6914063 & 1.5712891 & 3.773438 \\
\hline 2.6972656 & 1.5732422 & 3.785156 \\
\hline 2.7011719 & 1.5703125 & 3.777344 \\
\hline 2.6972656 & 1.5791016 & 3.773438 \\
\hline 2.6894531 & 1.5683594 & 3.777344 \\
\hline 2.6953125 & 1.5664063 & 3.777344 \\
\hline 2.6933594 & 1.5712891 & 3.777344 \\
\hline 2.6875 & 1.5732422 & 3.765625 \\
\hline 2.6875 & 1.5712891 & 3.785156 \\
\hline 2.6933594 & 1.5634766 & 3.785156 \\
\hline 2.6914063 & 1.5742188 & 3.777344 \\
\hline 2.6953125 & 1.5722656 & 3.769531 \\
\hline 2.6933594 & 1.5634766 & 3.777344 \\
\hline 2.6972656 & 1.5634766 & 3.769531 \\
\hline 2.6972656 & 1.5751953 & 3.785156 \\
\hline 2.6992188 & 1.5625 & 3.777344 \\
\hline 2.6953125 & 1.5732422 & 3.773438 \\
\hline 2.6992188 & 1.5712891 & 3.777344 \\
\hline 2.6816406 & 1.5742188 & 3.777344 \\
\hline 2.6933594 & 1.5761719 & 3.773438 \\
\hline 2.6972656 & 1.5761719 & 3.78125 \\
\hline 2.6992188 & 1.5644531 & 3.777344 \\
\hline 2.7050781 & 1.5703125 & 3.773438 \\
\hline 2.6894531 & 1.5693359 & 3.773438 \\
\hline 2.6972656 & 1.5712891 & 3.777344 \\
\hline 2.7011719 & 1.5732422 & 3.769531 \\
\hline 2.6972656 & 1.578125 & 3.773438 \\
\hline 2.6894531 & 1.5751953 & 3.78125 \\
\hline 2.6914063 & 1.5634766 & 3.773438 \\
\hline 2.6914063 & 1.5712891 & 3.773438 \\
\hline 2.6914063 & 1.5664063 & 3.773438 \\
\hline 2.6933594 & 1.5703125 & 3.78125 \\
\hline 2.6894531 & 1.5644531 & 3.773438 \\
\hline 2.6933594 & 1.5722656 & 3.777344 \\
\hline
\end{tabular}




\begin{tabular}{|c|c|c|}
\hline 2.6914063 & 1.5683594 & 3.777344 \\
\hline 2.7011719 & 1.5693359 & 3.765625 \\
\hline 2.6914063 & 1.5712891 & 3.78125 \\
\hline 2.6953125 & 1.5732422 & 3.769531 \\
\hline 2.6914063 & 1.5732422 & 3.765625 \\
\hline 2.6914063 & 1.5732422 & 3.78125 \\
\hline 2.6972656 & 1.5722656 & 3.769531 \\
\hline 2.6933594 & 1.5742188 & 3.769531 \\
\hline 2.6933594 & 1.5693359 & 3.78125 \\
\hline 2.6816406 & 1.5683594 & 3.769531 \\
\hline 2.6914063 & 1.5742188 & 3.769531 \\
\hline 2.6933594 & 1.5761719 & 3.769531 \\
\hline 2.6914063 & 1.5742188 & 3.769531 \\
\hline 2.6992188 & 1.5693359 & 3.78125 \\
\hline 2.6914063 & 1.5712891 & 3.773438 \\
\hline 2.6953125 & 1.5732422 & 3.78125 \\
\hline 2.6972656 & 1.5761719 & 3.777344 \\
\hline 2.6894531 & 1.5654297 & 3.773438 \\
\hline 2.6972656 & 1.5576172 & 3.773438 \\
\hline 2.6992188 & 1.5712891 & 3.777344 \\
\hline 2.6953125 & 1.5683594 & 3.773438 \\
\hline 2.6972656 & 1.5771484 & 3.78125 \\
\hline 2.6875 & 1.5703125 & 3.773438 \\
\hline 2.6953125 & 1.5654297 & 3.773438 \\
\hline 2.6914063 & 1.5732422 & 3.78125 \\
\hline 2.6875 & 1.5742188 & 3.773438 \\
\hline 2.6816406 & 1.5722656 & 3.789063 \\
\hline 2.6914063 & 1.5742188 & 3.78125 \\
\hline 2.6953125 & 1.5742188 & 3.773438 \\
\hline 2.6972656 & 1.5683594 & 3.773438 \\
\hline 2.6914063 & 1.5693359 & 3.773438 \\
\hline 2.7089844 & 1.5683594 & 3.773438 \\
\hline 2.6855469 & 1.5732422 & 3.765625 \\
\hline 2.6992188 & 1.5683594 & 3.777344 \\
\hline 2.6972656 & 1.5771484 & 3.777344 \\
\hline 2.6894531 & 1.5732422 & 3.777344 \\
\hline 2.6933594 & 1.5800781 & 3.78125 \\
\hline 2.6914063 & 1.5791016 & 3.777344 \\
\hline 2.6914063 & 1.5722656 & 3.78125 \\
\hline 2.6875 & 1.5771484 & 3.777344 \\
\hline 2.6875 & 1.5722656 & 3.769531 \\
\hline 2.6914063 & 1.5683594 & 3.78125 \\
\hline 2.703125 & 1.5712891 & 3.769531 \\
\hline
\end{tabular}




\begin{tabular}{|c|c|c|}
\hline 2.7050781 & 1.5751953 & 3.777344 \\
\hline 2.6875 & 1.5683594 & 3.777344 \\
\hline 2.6972656 & 1.5664063 & 3.777344 \\
\hline 2.7011719 & 1.5722656 & 3.773438 \\
\hline 2.7011719 & 1.5693359 & 3.773438 \\
\hline 2.6992188 & 1.5732422 & 3.777344 \\
\hline 2.7089844 & 1.5664063 & 3.785156 \\
\hline 2.7050781 & 1.5732422 & 3.777344 \\
\hline 2.6914063 & 1.5722656 & 3.773438 \\
\hline 2.6972656 & 1.5712891 & 3.765625 \\
\hline 2.6855469 & 1.5654297 & 3.777344 \\
\hline 2.6972656 & 1.5654297 & 3.777344 \\
\hline 2.6933594 & 1.5751953 & 3.777344 \\
\hline 2.6894531 & 1.5693359 & 3.785156 \\
\hline 2.6875 & 1.5732422 & 3.761719 \\
\hline 2.6914063 & 1.5722656 & 3.777344 \\
\hline 2.6933594 & 1.5742188 & 3.769531 \\
\hline 2.7011719 & 1.5712891 & 3.78125 \\
\hline 2.6914063 & 1.5751953 & 3.773438 \\
\hline 2.6933594 & 1.5683594 & 3.773438 \\
\hline 2.6933594 & 1.5683594 & 3.773438 \\
\hline 2.6894531 & 1.5742188 & 3.769531 \\
\hline 2.6992188 & 1.5703125 & 3.78125 \\
\hline 2.6914063 & 1.5615234 & 3.78125 \\
\hline 2.703125 & 1.5751953 & 3.777344 \\
\hline 2.6933594 & 1.5761719 & 3.773438 \\
\hline 2.6835938 & 1.578125 & 3.777344 \\
\hline 2.6914063 & 1.5712891 & 3.777344 \\
\hline 2.6933594 & 1.5722656 & 3.773438 \\
\hline 2.6914063 & 1.5644531 & 3.78125 \\
\hline 2.6953125 & 1.5664063 & 3.769531 \\
\hline 2.6914063 & 1.5771484 & 3.765625 \\
\hline 2.6894531 & 1.5664063 & 3.78125 \\
\hline 2.6992188 & 1.5712891 & 3.769531 \\
\hline 2.6914063 & 1.5712891 & 3.78125 \\
\hline 2.6914063 & 1.5712891 & 3.777344 \\
\hline
\end{tabular}




\section{Bibliography}

[1] M. P. Païdoussis, Fluid-Structure Interations: Slender Structures and Axial Flow, San Diego: Elsevier Academic Press, 2004.

[2] X. Zhang, Numerical and experimental investigations on vibration of simulated CANDU fuel bundles subjected to turbulent fluid flow, Toronto: Ryerson University, 2011.

[3] R. K. Peri, "Experimental Studies of Vibrations of Flexible Structures Induced by Axial Pipe Flow," Ryerson university, 2009.

[4] E. G. D. A. a. C. S. M.P. Païdoussis, "LINEAR AND NONLINEAR DYNAMICS OF CANTILEVERED CYLINDERS IN AXIAL FLOW PART 1: PHYSICAL DYNAMICS," Journal of Fluids and Structures, pp. 691713, 2002.

[5] Y. L. ,. J. L. Z.G. Liu, "Fluid-structure interaction of single flexible cylinder in axial flow," Computers \& Fluids, pp. 143-151, 2012.

[6] M. P. Païdoussis, "Dynamics of cylindrical structures subjected to axial flow," Journal of Sound and Vibration, pp. 365-385, 1973.

[7] Thaddeus F. Wnek, "Pressure Pulsations Generated by Centrifugal Pumps," N.D.. [Online]. Available: http://www.warrenpumps.com/resources/pressurepuls.pdf. [Accessed 20 March 2014].

[8] M. P. Païdoussis, "FLUIDELASTIC VIBRATION OF CYLINDER ARRAYS IN AXIAL AND CROSS FLOW: STATE OF THE ART," Journal of Sound and Vibration, pp. 329-360, 1981.

[9] M. P. P. Y. M.-S. E. de Langre, "Flutter of long flexible cylinders in axial flow," Fluid Mechanics, pp. 371-389, 2007.

[10] P. v. L. H. S. C. T. H. Higuchi, "Axial flow over a blunt circular cylinder with and without shear layer reattachment," Journal of Fluids and Structures, pp. 949-959, 2006.

[11] B. A. Olshausen, "PSC 129 - Sensory Processes: Aliasing," 10 October 2000. [Online]. Available: http://redwood.berkeley.edu/bruno/npb261/aliasing.pdf. [Accessed 27 January 2015].

[12] T. Irvine, "SHOCK AND VIBRATION RESPONSE SPECTRA COURSE," N.D.. [Online]. Available: http://www.vibrationdata.com/Course_Units/UNIT15.pdf. [Accessed 15 September 2014].

[13] D. J. Inman, Engineering Vibration, Upper Saddle River: Pearson Education, Inc., 2008. 
[14] N. Doertenbach, "The calculation of Grms," N.D.. [Online]. Available:

http://www.dfrsolutions.com/uploads/services/HALT_grms_calculation_ndoertenbach.pdf. [Accessed 10 December 2014].

[15] P. F. R. P. D. H. M. T. G. M. R. H. Stalin A Boctor, Electrical Concepts and Applications, St. Paul: West Publishing Company, 1997.

[16] F. M. White, Fluid Mechanics, New York: McGraw-Hill, 2008.

[17] T. Irvine, "SHOCK AND VIBRATION RESPONSE SPECTRA COURSE Unit 15: Integration of a Power Spectral Density Function," [Online]. Available: http://www.vibrationdata.com/Course_Units/UNIT15.pdf. [Accessed 14 November 2014].

[18] M. L. Ilsup Chung, "An experimental study on fretting wear behavior of cross-contacting Inconel 690 tubes," Nuclear Engineering and Design, pp. 4103-4110, 2011.

[19] K.-T. Kim, "Applicability of out-of-pile fretting wear tests to in-reactor fretting wear-induced failure time prediction," Journal of Nuclear Materials, pp. 364-371, 2013.

[20] P. R. Rubiolo, "Probabilistic prediction of fretting-wear damage of nuclear fuel rods," Nuclear Engineering and Design, pp. 1628-1640, 2006.

[21] W. N. Association, "Nuclear power in the world today," April 2014. [Online]. Available: http://www.world-nuclear.org/info/current-and-future-generation/nuclear-power-in-the-worldtoday/. [Accessed 16 January 2015].

[22] M. W. W. Shoei-sheng Chen, "Parallel-Flow-Induced Vibrations of Fuel Rods," Nuclear Engineering and Design, pp. 253-278, 1972.

[23] M. P. Païdoussis, "A REVIEW OF FLOW-INDUCED VIBRATIONS IN REACTORS AND REACTOR COMPONENTS," Nuclear Engineering and Design, pp. 31-60, 1982.

[24] F. Peterka, "FLOW-INDUCED IMPACT OSCILLATION OF A SPHERICAL PENDULUM," Journal of Fluids and Structures, pp. 627-650, 1991.

[25] "Nuclear Power in Canada," December 2014. [Online]. Available: http://www.worldnuclear.org/info/Country-Profiles/Countries-A-F/Canada--Nuclear-Power/. [Accessed 2015 February 4]. 